University of Louisville

ThinkIR: The University of Louisville's Institutional Repository

Electronic Theses and Dissertations

$5-2020$

\title{
Effects of Design Autonomy on the Flow Experience
}

Antonio F Coriano

University of Louisville

Follow this and additional works at: https://ir.library.louisville.edu/etd

Part of the Ergonomics Commons, and the Industrial Engineering Commons

\section{Recommended Citation}

Coriano, Antonio F, "Effects of Design Autonomy on the Flow Experience" (2020). Electronic Theses and Dissertations. Paper 3352.

https://doi.org/10.18297/etd/3352

This Master's Thesis is brought to you for free and open access by ThinkIR: The University of Louisville's Institutional Repository. It has been accepted for inclusion in Electronic Theses and Dissertations by an authorized administrator of ThinkIR: The University of Louisville's Institutional Repository. This title appears here courtesy of the author, who has retained all other copyrights. For more information, please contact thinkir@louisville.edu. 


\title{
EFFECTS OF DESIGN AUTONOMY ON THE FLOW EXPERIENCE
}

\author{
By \\ Antonio Francisco Coriano \\ B.S. Industrial Engineering, University of Louisville, May 2019
}

\begin{abstract}
A Thesis
Submitted to the Faculty of the

University of Louisville

as Partial Fulfillment of the Requirements
\end{abstract}

for the Professional Degree

\section{MASTER OF ENGINEERING}

Department of Industrial Engineering

May 2020 



\section{EFFECTS OF DESIGN AUTONOMY ON THE FLOW EXPERIENCE}

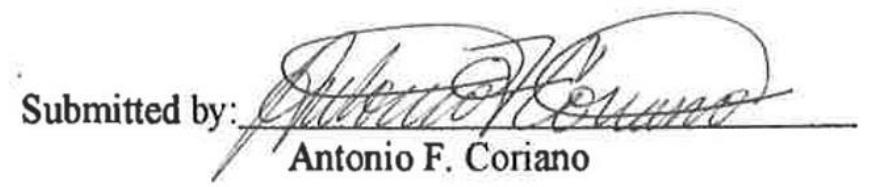

A Thesis Approved On

17 APRIL 2020

\section{(Date)}

by the Follgwing Reading and Examination Committee:
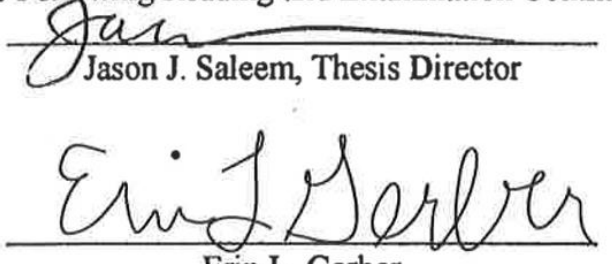

Erin L. Gerber

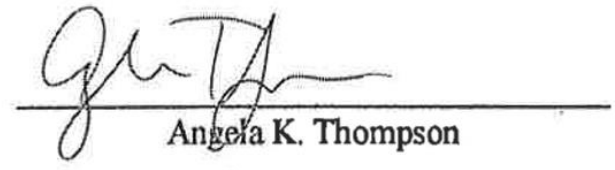




\section{ACKNOWLEDGMENTS}

Let it be known that there are countless individuals who have helped me along this journey. Take this as acknowledgement to all of those who are not named.

I would like to thank the thesis committee and other professors who helped bring this thesis to life:

Dr. Erin Gerber, Dr. Angela Thompson, Dr. Brian Robinson, and Dr. Keith Lyle

A special thank you to the committee director and my mentor for everything you have done for me, the list is too long to mention:

Dr. Jason Saleem

Thank you to the Ford family for being my home away from home during my time at the University of Louisville:

Treverton Ford, Karen Olde-Ford, Bryan Ford, and Shawn Ford

A very special thank you to my best friend and brother who first gave me the book Flow and took this entire journey alongside me:

\section{Dylan Ford}

Thank you to my family who have supported me endlessly throughout my life and who have sacrificed so much to give me the opportunities I have:

Francisco Coriano, Emerita Coriano, and The Coriano Family, Joanne Leone, Robert Barber, Susan Chianese, Robert Chianese, Scott Chianese, and The Chianese Family

Finally, to those which I owe my life and all the love that I possess, my parents: Franky Coriano and Doreen Chianese 


\begin{abstract}
Most modern workplace settings are laden with operating procedure aimed at standardizing action in the name of efficiency. The cost of this standardization is the autonomy of the operator. Mihaly Csikszentmihalyi stated the problem concisely in his 1975 work Beyond Boredom and Anxiety “... [M]ost of the institutions that take up our time...are organized around the assumption that serious work is grim and unpleasant. Because of this assumption, most of our time is spent doing unpleasant things". An experiment was created to study and better understand how to redress this harmful situation. Sixteen subjects were given a SolidWorks computer aided design task with varying levels of design instruction. The subjects then completed the Flow Short Scale and Computer System Usability Questionnaire to measure their perceived flow experience and their perceived usability of the system. No significant difference was found between the flow or usability between design prescriptions using a two-sample t-test. Several correlational relationships were present between the scales using a Spearman's rank order coefficient. With a larger sample size, more significant relationships may appear between the levels of design prescription. The implications of the correlational relationship suggest that operator perceived flow could be used as a marker for a healthy and sustainable system.
\end{abstract}


TABLE OF CONTENTS

EFFECTS OF DESIGN AUTONOMY ON THE FLOW EXPERIENCE ........................ ii

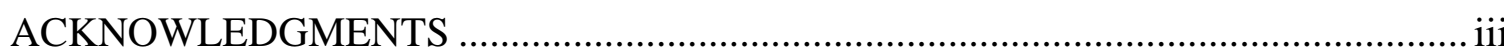

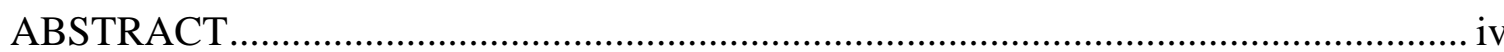

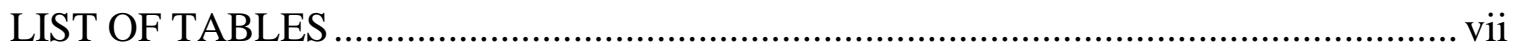

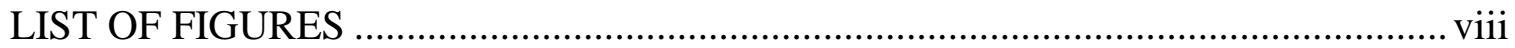

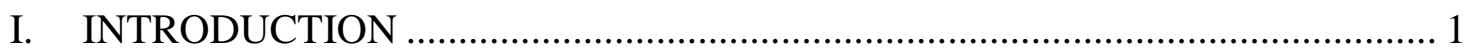

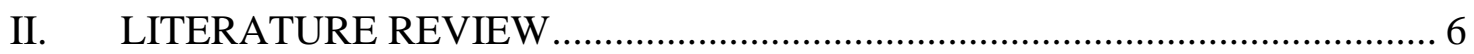

A. Flow: Preconditions, Components, and Consequences ..................................... 6

B. Cognitive Evaluation Theory, Autonomy, and Locus of Causality ............... 14

C. Usability and the Technology Acceptance Model......................................... 17

D. State of Current Literature........................................................................ 19

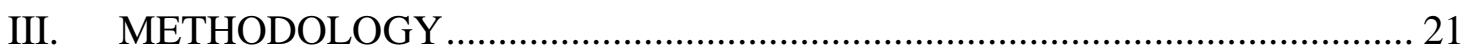

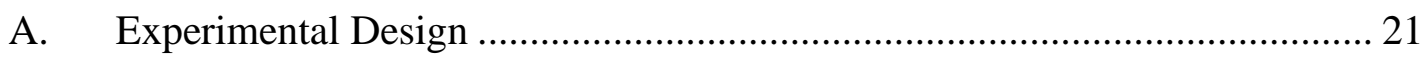

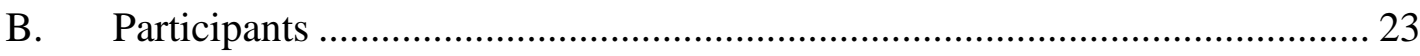

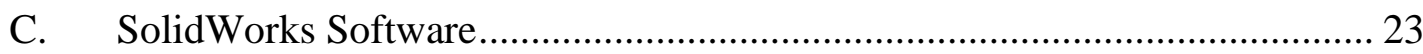

D. Selection of Modeling Task...................................................................... 24

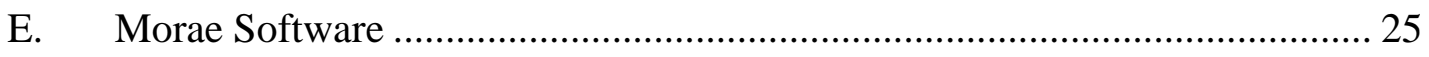

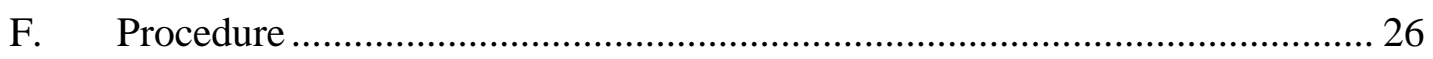

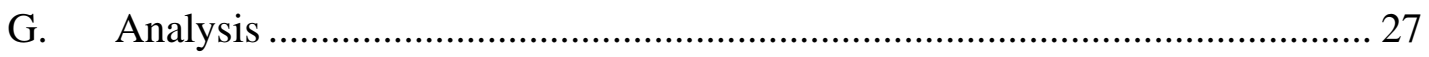

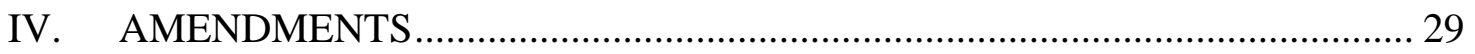

A. Experimental Design and Analysis........................................................... 29

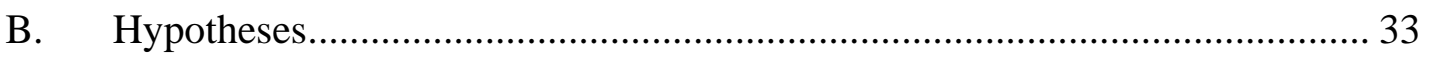

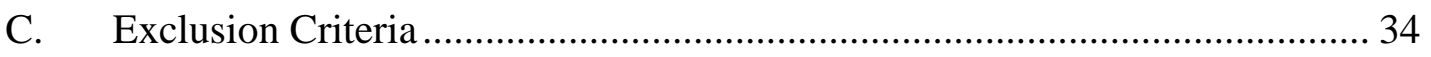

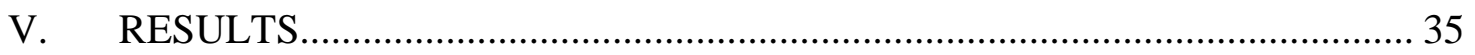

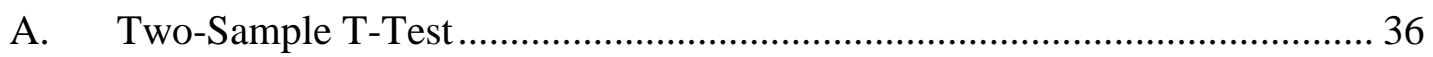

C. Spearman's Rank Order Coefficient.............................................................. 40

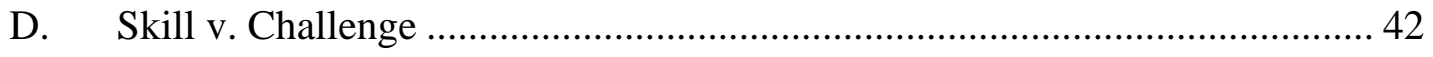

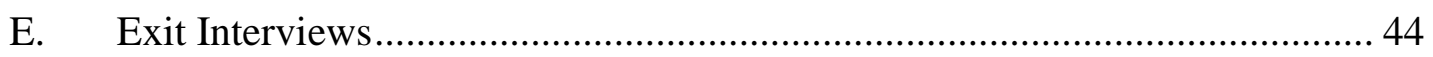

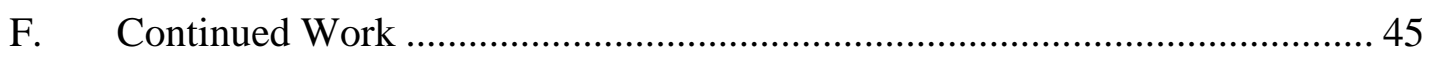

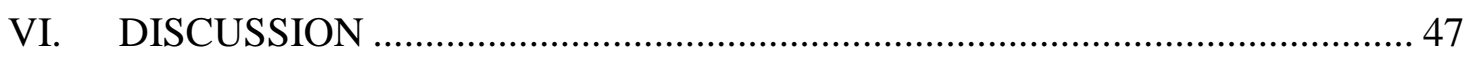

A. Interpretation of Results .......................................................................... 47

B. Skills v. Challenge and Continued Work ……………………………........... 49

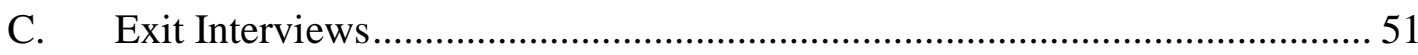

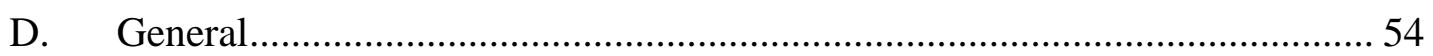




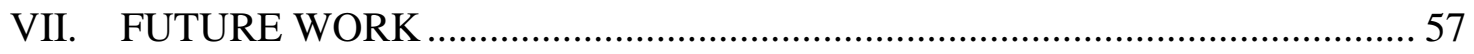

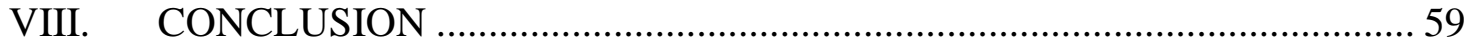

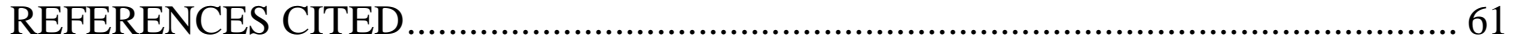

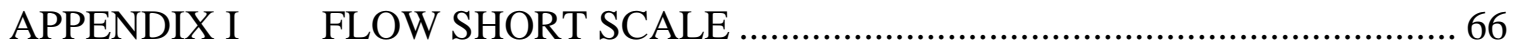

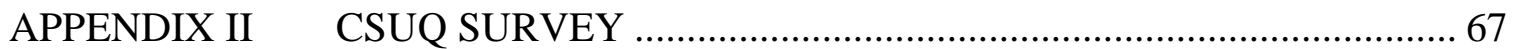

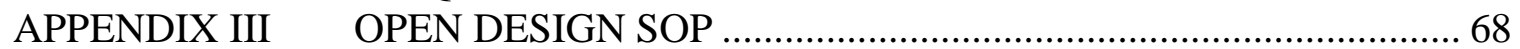

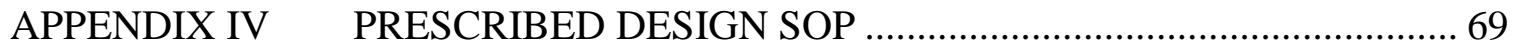

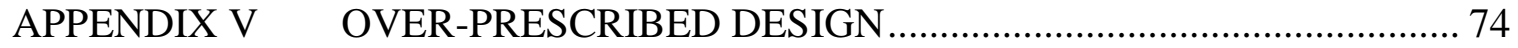

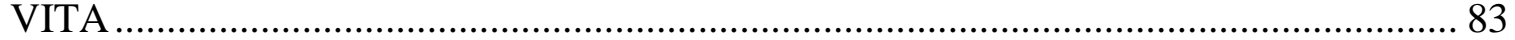




\section{LIST OF TABLES}

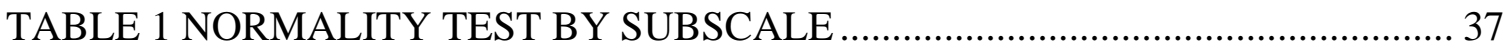

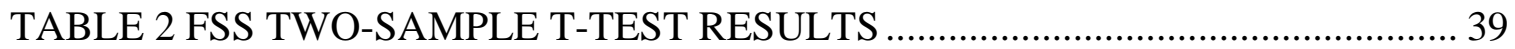

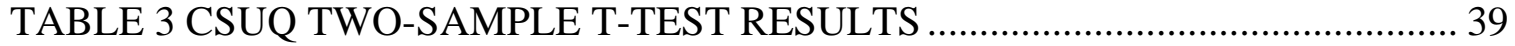

TABLE 4 SPEARMAN'S RANK ORDER COEFFICIENTS FOR OPEN DESIGN ..... 41

TABLE 5 SPEARMAN'S RANK ORDER COEFFICIENTS FOR PRESCRIBED

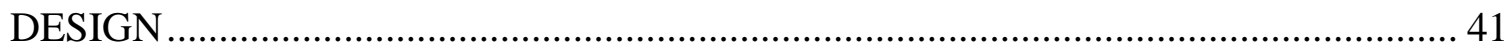

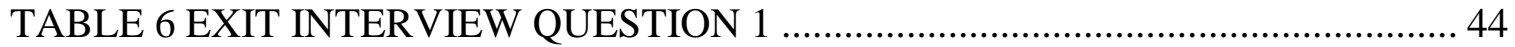

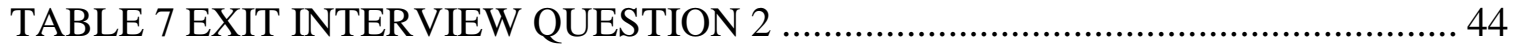

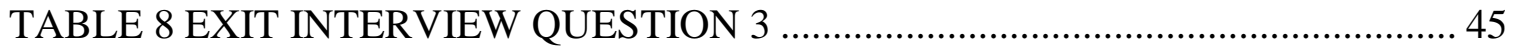

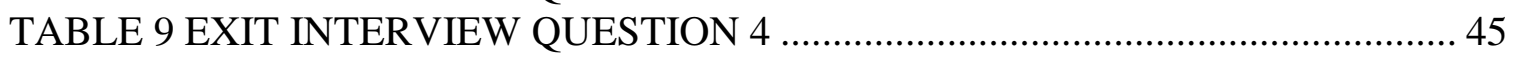

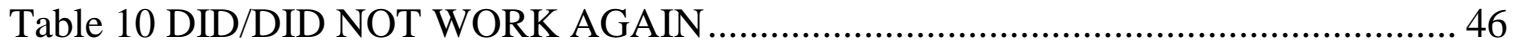




\section{LIST OF FIGURES}

FIGURE 1 - The Original Flow Model (adapted from Moneta, 2012) ............................ 8 FIGURE 2 - The Mode Of The Precondition, Components, And Consequences Of The Flow Experience (adapted from Landhäußer \& Keller, 2012) ...................................... 9 FIGURE 3 - The Revised Flow Model (adapted from Landhäußer \& Keller, 2012) ....... 10 FIGURE 4 - Experimental Design ............................................................................. 21

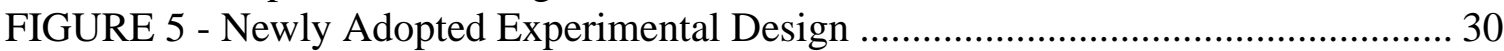

FIGURE 6 - N = 11 Participants Tested Before Amendments ...................................... 31

FIGURE 7 - N = 11 Participants Adapted To New Experimental Design ...................... 31

FIGURE 8 - N = 16 Participants If Original Experimental Design Used....................... 32

FIGURE 9 - SolidWorks Self-Rating Results ............................................................ 35

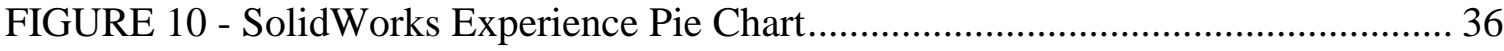

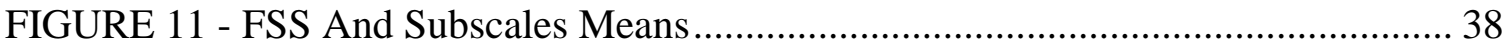

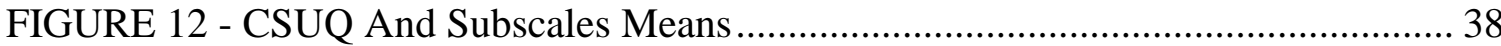

FIGURE 13 - Original Flow Model With Participant Response Plotted........................ 43

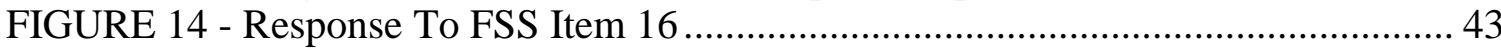

FIGURE 15 - FSS + Subscale - Did/Did Not Work Again ........................................ 46 


\section{INTRODUCTION}

Consider a student who is totally absorbed in the completion of an assignment, a factory worker who finds the work to be engaging as opposed to a means to a paycheck, and a chess master who loves the game because time seems to fade away whenever in a challenging match. Each of these subjects shares a common experience, flow. Flow as a psychological phenomenon was initially reported by Mihaly Csikszentmihalyi in his 1975 work, Beyond Boredom and Anxiety. For the purpose of this thesis, flow is defined as a state in which an individual is completely immersed in an activity without reflective selfconsciousness but with a deep sense of control (Engeser \& Schiepe-Tiska, Historical Lines and an Overview of Current Research on Flow, 2012). The experiential state of flow is characterized by a combination of several specific aspects, namely, (1) concentration, (2) a merging of action and awareness, (3) reduced self-consciousness, (4) a sense of control, (5) a transformation of time, and (6) an experience of the activity as intrinsically rewarding (Landhäußer \& Keller, 2012). Coined the "optimal experience" by Csikszentmihalyi, flow has shown positive emotional and psychological influence on those who report experiencing it frequently.

Flow, as an experience, facilitates creativity in the subject. Current manufacturing efficiency techniques may be hindering the ability of workers to enter flow state during their work experiences. Cognitive Evaluation Theory (CET), a theory which has been closely linked to flow (Abuhamdeh, 2012), suggests that humans require the perception of autonomy in order to experience intrinsic task motivation. This has been well supported empirically (Deci, 1971; Zuckerman et al., 1978). It may be that the heavily controlled 
manufacturing environment, filled with standard operating procedures (SOPs), which are referred to as prescribed design throughout this thesis, could ultimately steal the autonomy, and therefore the enjoyment of the worker. This could have many hidden consequences and is worthy of investigation. Although there is no doubt that SOP has its place as a regulator of compliance to communication and industry standards, the misuse of SOPs and its effect on worker autonomy has yet to be measured in the literature. The literature on flow and autonomy is robust; therefore, generating a meaningful connection between the effect of SOP on the flow experience was the primary goal of this thesis.

A central precursor to the flow experience is a suitable balance of skill and challenge (Csikszentmihalyi M. , 1975). Facilitating this balance could have operational significance in the training and maintenance of a workforce. Introducing SOPs could allow for an inexperienced operator to have a flow experience while performing a complex task. The same SOP could also hinder an experienced operator from having a flow experience. The manipulation of the skill-challenge balance is central to flow research.

With a sharpened understanding of flow and how it is affected by autonomy, interest turns to application. Can a user experience designer harness the aspects of flow to create an immersive experience, or is flow strictly subjective? This question has not yet been answered by the literature. It was a secondary goal of this thesis to pave the way for future research looking to discover the relationships of this complex question. Understanding user experience is undoubtedly an important part of any product cycle. Flow is a welldefined and measurable user experience which through the manipulation of interface design, could be elicited. The first step in understanding how to design for flow as a user 
experience is to better understand what user interaction experiences produce flow, which will be achieved through the careful study of the effects of SOP on the flow experience.

The need for the proposed study has been established by the lack of current literature on the subjects. Therefore, three questions are proposed, "What type of design task is more likely to elicit flow state?", "How does the interaction between experience and design task affect flow?", and "What is the relationship, if any, between product usability and the ability of a user to achieve flow state?". An experiment was designed to complete an analysis of the effects of perceived autonomy on the subjective flow user experience. In order to analyze the relationship between autonomy and flow, this experiment used a sample population of college-aged engineering students complete a modeling task in the SolidWorks computer-aided design software. Two independent variables were introduced. The first, design autonomy, introduced three levels of design prescription: open, prescribed, and over-prescribed. The second, experience, introduced three levels of experience: beginner, intermediate, advanced; each representing a given subject's experience with the SolidWorks program. For each level of experience, all three design prescriptions were tested. The subject's perceived flow was measured by the Flow Short Scale (Reinberg, Vollmeyer, \& Engeser, 2003). Subjects were also asked to rate the usability of the program through the IBM Computer System Usability Questionnaire (CSUQ; Lewis, 1995). Based on review of the literature, hypotheses are proposed that correspond to the study questions:

- "What type of design task is more likely to elicit flow state?"

Hypothesis 1: Subjects presented with an open design will be more likely to report flow than subjects presented with a prescribed design. 
- "How does the interaction between experience and design task affect flow?"

Hypothesis 2: An inverse relationship will be present showing less experienced subjects experiencing flow with more prescriptive design and more experienced subjects experiencing flow with less prescriptive design.

- "What is the relationship, if any, between product usability and the ability of a user to achieve flow state?"

Hypothesis 3: Users who report high usability while interacting with a product, as measured by the CSUQ, are more likely to report experiencing flow. A significant difference in Flow Short Scale scores would indicate a difference in the flow experienced by the subjects.

The first and second hypotheses were based firmly on links between Flow and Cognitive Evaluation Theory (CET; Deci \& Ryan, 1985). By introducing an independent variable governing autonomy (levels of design prescription) the study tested the relationship between perceived flow and autonomy. An open design may also be more likely to result in the designer reporting an autotelic experience, which is a key contributor to achieving flow state (Csikszentmihalyi M., flow The Psychology of the Optimal Experience, 1990). By introducing an independent variable governing experience, a greater understanding of the effects of autonomy on flow can be achieved. The effects of extrinsic regulatory styles, in contrast to intrinsic or self-regulatory styles, have been described by Deci and Ryan (2000).

The third hypothesis was also based on the literature. Links between Flow and Usability Engineering have been established in their infancy by creating theoretical links between the Technology Acceptance Model (TAM) and the flow-based concept of 
cognitive absorption (Lowry, Gaskin, Twyman, Hammer, \& Roberts, 2012). The TAM considers key usability concepts, notably perceived usefulness and perceived ease-of-use, as factors that influence a user's decision about how and when they will use a given technology. The construct of cognitive absorption is underpinned by several subconstructs, joy, control, curiosity, focused immersion, and temporal dissociation. New models suggest the use of cognitive absorption as a key mediator of perceived ease-of-use (HMSAM; Lowry et al., 2012). I hypothesized that measuring both flow and usability will bring experimental validity to these theories, such that the theoretical link between flow and usability can be moved into the realm of practice. 


\section{LITERATURE REVIEW}

Three areas of research were reviewed and analyzed for the research questions of this proposed study: (1) the phenomenon of flow and its preconditions, components, and consequences; (2) Cognitive Evaluation Theory as it relates to autonomy and locus of causality; and (3) usability and the technology acceptance model (TAM). All these areas are related to subjective user experience and overall research describing motivation and more abstractly, flow. The collective findings indicate the power of flow and perceived autonomy as a determining factor in a positive user experience and the negative effects of extrinsic motivational regulation styles on perceived autonomy. The gaps in the literature verify the need for a stronger link to be created between flow theory and its practical application as is suggested in the study described above.

\section{A. Flow: Preconditions, Components, and Consequences}

The term flow was coined by Mihaly Csikszentmihalyi in 1975 after several years of research into play activities, creativity, and artists' personalities (Csikszentmihalyi \& Bennett, 1971; Csikszentmihalyi \& Getzels, 1973; Getzel \& Csikszentmihalyi, 1966). Thetstarting point of his research can best be described by Csikszentmihalyi himself:

In a world supposedly ruled by the pursuit of money, power, prestige, and pleasure, it is surprising to find certain people who sacrifice all those goals for no apparent reason: people who risk their lives cimbing rocks, who devote their lives to art, and who spend their energy playing chess. By finding out why they are willing to give up material rewards for the elusive experience of performing enjoyable acts, we hope to learn something that will allow us to make everyday life more meaningful. At present, most 
of the institutions that take up our time-schools, offices, factories-are organized around the assumption that serious work is grim and unpleasant. Because of this assumption, most of our time is spent doing unpleasant things. By studing enjoyment, we might learn how to redress this harmful situation. (Csikzenmtmihalyi 1975, p.1)

There is a high level of agreement on the definition of flow amongst the flow research community. The modern definition of flow is a state in which an individual is completely immersed in an activity without reflective self-consciousness but with a deep sense of control (Engeser, 2012). The experiential state of flow is characterized by a combination of several specific aspects, namely, (1) concentration, (2) a merging of action and awareness, (3) reduced self-consciousness, (4) a sense of control, (5) a transformation of time, and (6) an experience of the activity as intrinsically rewarding (Landhäußer \& Keller, 2012). This componential organization is key to defining the flow phenomenon. It provides flexibility to study individual components while holding to a scientifically meaningful concept that is intuitively understood based on one's own experience.

The earliest flow model partitions the world of experience in three main stages - flow, anxiety, and boredom - that are represented as nonoverlapping areas of a challenge by skill Cartesian space (FIGURE 1; Moneta, 2012). The original model and many future variants, like the quadrant model (Csikszentmihalyi \& LeFevre, 1989), suggest that the flow experience arises when the both skill and challenge are above the individual's mean and in balance. Landhäußer and Keller (2012) suggest that, for the most part, authors did not investigate correlates of consequences of the flow experience but those of a skill-demands compatibility. It should be noted that challenges and demands are used interchangeably, dependent on the author of the study. In order to model flow more accurately, Landhäußer and Keller (2012) present a model of the preconditions, components, and consequences of 
the flow experience (FIGURE 2). This is the most methodological way to describe the flow experience and will be evaluated in detail.

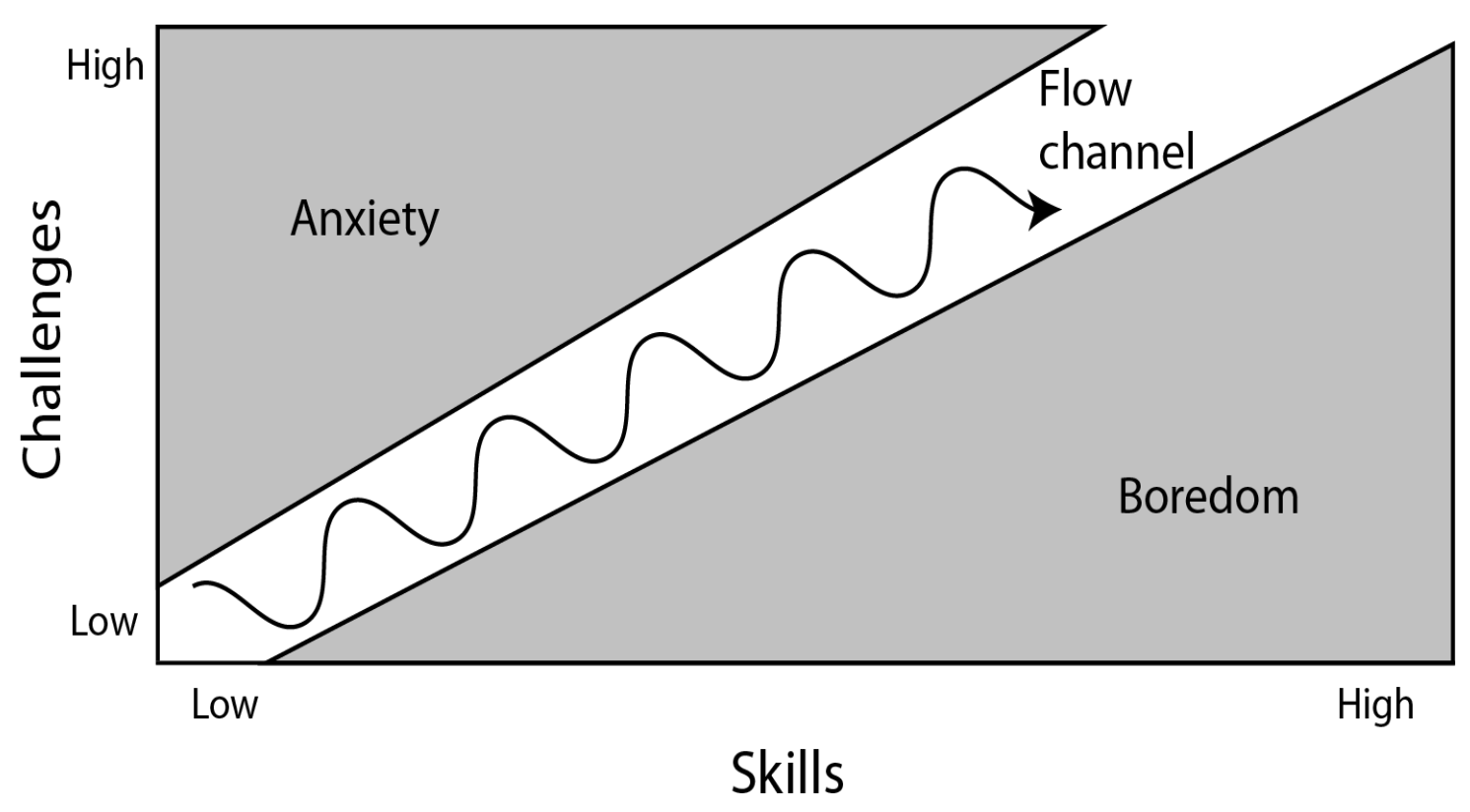

FIGURE 1 - The Original Flow Model (adapted from Moneta, 2012) 


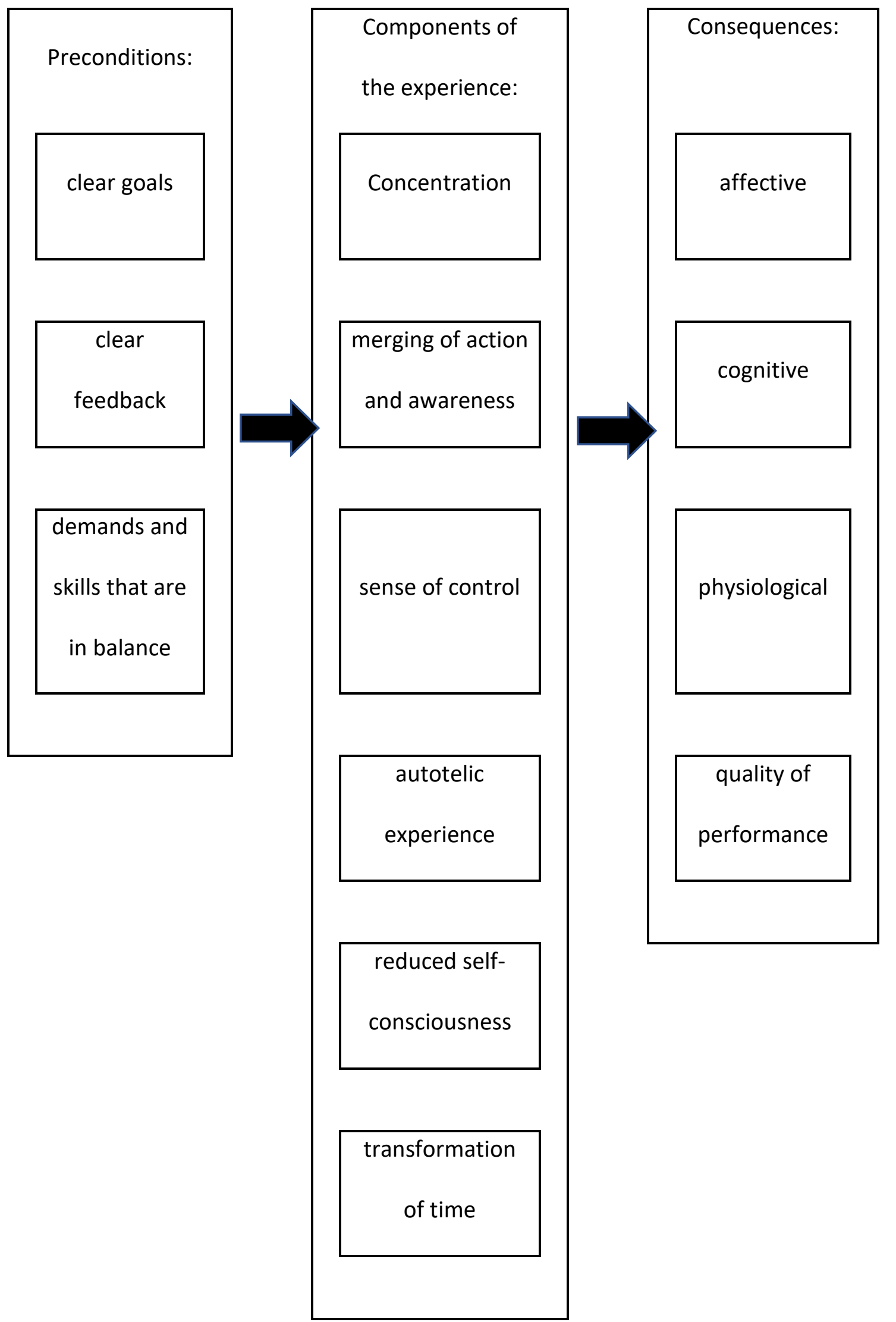

FIGURE 2 - The Mode of the Precondition, Components, and Consequences of the Flow Experience (adapted from Landhäußer \& Keller, 2012) 
The preconditions of flow, as modeled by Landhäußer and Keller (2012), are clear goals, clear feedback, and demands and skills that are in balance. Without these preconditions, the flow experience cannot arise. A slight, yet meaningful modification to the skill-demand balance is the addition of the individual's subjective value of the activity. Demand, or challenge, can be described as the opportunities for action and skills can be defined as action capabilities (Csikszentmihalyi 1975, p. 49), therefore, with grater capability to successful engage in action opportunities, flow may arise. In other words, an increase in the perceived fit of skills and task demands should increase the intensity of the flow experience. Similarly, while an increase in the subjective value of the activity cannot elicit the flow experience on its own, when coupled with the perceived fit, it can also increase the intensity of the flow experience. Keller and Landhäußer (2012) present the revised flow model: Flow intensity as a function of perceived fit and subjective value of the activity (FIGURE 3).
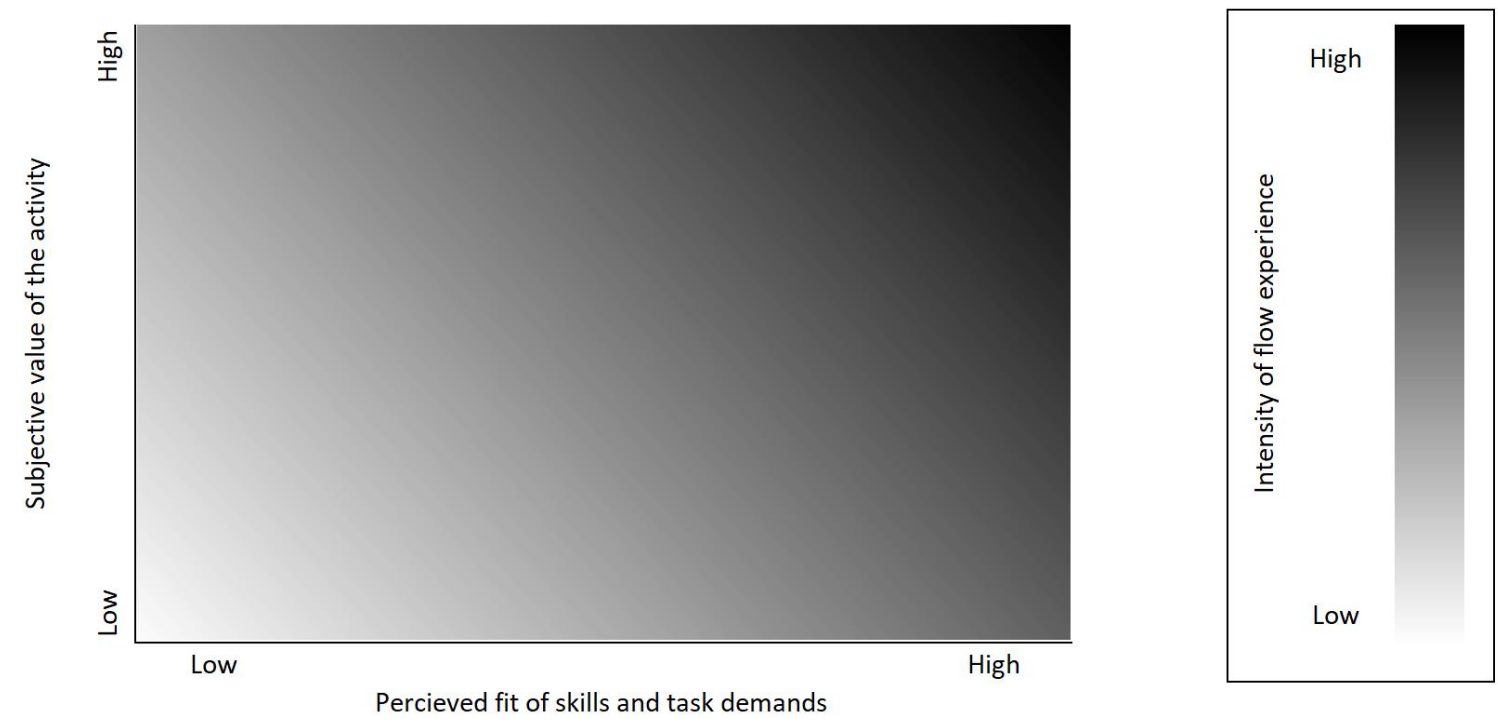

FIGURE 3 - The Revised Flow Model (adapted from Landhäußer \& Keller, 2012) 
The components of the flow experience are concentration, merging of action and awareness, sense of control, autotelic experience, reduced self-consciousness, and transformation of time (Figure 2; Landhäußer \& Keller, 2012). Some of the components can be understood without explanation, while others need some description. In order to simplify the components of flow the concept of cognitive absorption (CA) is introduced. CA is a second-order construct comprised of five first-order constructs: control, curiosity, heightened enjoyment, focused immersion, and temporal dissociation (Aragwal \& Karahanna, 2000). When compared to the components of the flow experience, CA seems to directly account for sense of control and transformation of time. One can argue that the CA construct of focused immersion accounts for the flow components merging of action and awareness and reduced self-consciousness; although, equating them may be oversimplification. Finally, curiosity and heightened enjoyment are closely linked to the autotelic experience.

Describing the autotelic experience can become as complex as describing the flow experience itself. The autotelic experience is at the heart of the flow experience and covers enjoyment, involvement, and intrinsic motivation. The term "intrinsic" can be interpreted in distinct ways but for the scope of this study it will be described in terms of Self Determination Theory (SDT): People are seen to be intrinsically motivated when they perceive their behavior as self-determined; that is, their needs for autonomy and competence are satisfied (Deci \& Ryan, 1980, 1985). Intrinsic motivation can be contrasted with extrinsic motivation, which in terms of SDT, is motivation that is not selfdetermined (i.e. money, power, praise). 
The flow components merging of action and awareness and reduced selfconsciousness should be further noted as well. The merging of action and awareness is described by Csikzentmihalyi (1975, p. 39): a person is aware of its actions but not of the awareness itself; "You do not see yourself as separate form what you are doing". He later goes on to describe loss of self-consciousness: considerations about self become irrelevant; this could be described as "the loss of ego," "self-forgetfulness," "transcendence of individuality," or "fusion with the world" (p. 42); "You yourself are in an ecstatic state to such a point that you feel as though you almost don't exist...I just sit there watching it in a state of awe and wonderment. And it just flows out by itself' (p. 44). Some of the awe and wonderment have been elucidated by Dietrich (2004) who described flow in terms of neuroscience and functional magnetic resonance imaging (fMRI) as resulting from a downregulation of prefrontal activity in the brain (Hypofrontality, Dietrich 2003): During flow, well-trained activites are performed without interference of a conscious control system, which makes the process very fast and efficient. The affected brain areas noted by Dietrich overlap a brain network called the Default Mode Network (DMN; Raichle et al., 2001). The DMN has been suggested as the brain network which governs resting state function such as self-reflection and daydreaming. Variation in DMN activity has been linked to greater academic success and improved memory (Immordino-Yang et al., 2012; Raichle 2015; Wig et al., 2008). These fMRI results can also been seen as physiological consequences of the flow expereience.

The consequences of flow modeled by Landhäußer and Keller are categorical. They are listed as affective, cognitive, phsyiological, and quality of perfomance. In the current literature there is very little on the causal relationship between a skill-demands 
compatability and affect. With most of the data being correlational (Landhäußer, Keller, \& Frommherz, 2011; Schüler, 2007), the best way to understand the possible consequences of flow is to refer to the theory. Moneta (2004) wrote:

[F]low theory states that flow has an (...) indirect effect on subjective well-being by fostering the motivation to face and master increasingly difficult tasks, thus promoting lifelong organismic growth. In particular, flow theory states that the frequency and intensity of flow in everyday life pinpoint the extent to which a person achieves sustained happiness through deliberate striving, and ultimately fulfills his or her growth potential (p.116).

For more information on the studied affective and cognitive consequences of flow, reference Landhäußer and Keller (2012). For more information on the studied physiological consequences of flow, reference (Pfiefer, 2012).

Concerning the measurement of flow, this thesis will employ the Flow Short Scale (FSS; Appendix I) by Rheinberg, Vollmeyer, and Engeser (2003). The FSS consists of two major subscales with items 1-10 measuring the components of flow experience and items 11, 12, and 13 measuring the percieved importance or percieved outcome importance. The subscale governing the flow items can further be broken down into fluency of performance (items 2, 4, 5, 7, 8, 9) and absorption by activity (items 1, 3, 6, 10). Three aditional items are appended to measure demand, skills, and the percieved fit of demands and skill (Engeser, 2012).

Armed with an understanding of flow as an experiential state which arises from a finite set of preconditions with undefined affective consequences, it is clear that more research must be done concerning the latter concepts. While those are an important issue in this field, they were beyond the scope of this thesis. This thesis understood how flow arises as a user experience by studying the effects of percieved autonomy on experiencing 
flow. This was done in hopes of laying down the infrastructure for future studies on the affective consequence of the flow experience in this general context.

\section{B. Cognitive Evaluation Theory, Autonomy, and Locus of Causality}

Cognitive Evaluation Theory (CET) is a sub theory within self-determination theory (Deci \& Ryan, 1985) that aims to explain the conditions that elicit and sustain intrinsic motivation. According to CET, humans enjoy activities to the extent that they satisfy the fundamental needs of competence and autonomy (Abuhamdeh, 2012). CET, like flow theory, emphasizes optimal challenge as an important condition for enjoyment. According to CET, "it is success at optimally challenging tasks that allows people to feel a true sense of competence" (Deci \& Ryan, 2000, p. 260). CET at its root aims to describe what motivates humans to perform tasks. As described in the previous section, intrinsic motivation is a component of the flow experience; CET is one way to better understand from what intrinsic motivation arises. The perceived competence proposition is briefly described to provide context for CET but is ultimately beyond the scope of this thesis. The focus of this section is on the perceived autonomy proposition and its relationship to flow.

Perceived competence represents the degree to which an individual perceives him/herself to be competent at a given activity (Abuhamdeh, 2012). Deci and Ryan (1985) describe the perceived competence proposition as such: "Simply stated, we would expect a close relationship between perceived competence and intrinsic motivation such that the more competent a person perceives himself to be at some activity, the more intrinsically motivated he will be at that activity" (p. 58). The relationship between CET and flow theory is apparent, with Deci and Ryan directly linking the theoretical concepts of 
perceived competence and intrinsic motivation, which is framed as a component of the flow experience (cf. FIGURE 2; Literature review, A). Utilizing CET as a guide to understand the motivational component of flow in general is logical and supported by the literature. Perceived competence appears to promote enjoyment in the context of performance-related activities (Reeve \& Deci, 1996; Blanck, Reis, \& Jackson, 1984; Vansteenkiste \& Deci, 2003), when performance-related concerns are minimal or absent, perceived competence may have no effect on enjoyment at all.

CET's perceived autonomy proposition states that events that increase a person's perceived autonomy while performing a certain behavior will increase intrinsic motivation for that behavior, whereas events that decrease perceived autonomy will decrease intrinsic motivation (Deci \& Ryan, 1985). The concept of autonomy is not elemental in flow theory, as Deci and Ryan (2000) state:

Perhaps the most important [difference between CET and flow theory] is that flow theory does not have a formal concept of autonomy, instead basing intrinsic motivation only in optimal challenge (which as a concept, is relevant primarily to competence rather than autonomy). SDT, on the other hand, has always maintained that even optimal challenges will not engender intrinsic motivation or flow unless people experience themselves as autonomous in carrying them out-that is, unless the behaviors have I-PLOC [internal perceived locus of causality]. Although Csikszentmihalyi has at times referred to the idea of autonomy, it has not been represented as a formal element in the theory (p. 261).

CET still directly relates autonomy and intrinsic motivation, especially in the more complex case of activities which are not performance-related; in other words: activities which have little extrinsic motivation factors.

Based on the overall literature, a relationship arises: The more extrinsic the motivation the less likely flow is to arise, and the more intrinsic the motivation the more likely flow is 
to arise (Csikszentmihalyi M. , 1990). This is a general relationship which is an undertone of flow theory. Work intuitively is largely extrinsically motivated. For example, completing $\mathrm{X}$ units of production will earn the operator a bonus. In this case, the operator is motivated by monetary gain to be productive. For the operator to produce most efficiently, a process engineer will often provide standard operating procedure (SOP) as a guideline. Frequently, the operator follows the steps provided until they have memorized the process exactly as they were directed to do it, completely outsourcing their process knowledge and effectively rendering them as a medium through which the SOP acts on the process. This relationship effectively eliminates the operator's autonomy and therefore, according to CET, their intrinsic motivation. In this current state, the operator is driven strictly by the extrinsic reward of a paycheck or the benefits provided by the company employing them. Interestingly, Csikszentmihalyi and LeFevre (1989) showed that using the experience sampling method (Csikszentmihalyi \& Larson, 1987), the majority of flow experiences are reported when working, not when in leisure. However, respondents are more motivated in leisure than in work, regardless of the quality of experience. This disconnect may be explained by CET's perceived autonomy proposition.

The first two research questions to be addressed in this thesis aim to provide insight into the working relationship between flow and autonomy. Standard operating procedure is defined by Merriam-Webster as established or prescribed methods to be followed routinely for the performance of designated operations or in designated situations. With that definition in mind, the introduction of a variable, level of prescription, was proposed. The level of prescription was hypothesized to have an inverse relationship with perceived autonomy. The greater the level of prescription, or in this case, the more constrained the 
directions in the SOP, the less autonomy will be perceived by the subject. Considering the literature on CET, this means the greater the level of prescription, the less intrinsic motivation will be experienced by the subject.

This relationship alone may not alone be enough to predict flow state. Therefore, a second variable, experience, was proposed. It was hypothesized that consistent with CET, no level of experience will report flow state for an overly prescribed design task. It is possible though, that SOP will satisfy the preconditions of flow for inexperienced subjects, specifically the need for clear goals and feedback, which may have been absent given an open (non-prescriptive) design. The contrary may be true with experienced subjects who were hypothesized to experience more flow as prescription decreases, experiencing flow most intensely when given an open design.

A preliminary relationship between flow and autonomy can be established through the manipulation of level of prescription and level of experience. Creating a stronger link between CET and flow theory may prove invaluable for better understanding how motivation effects the flow experience. It should be noted that the connection between SOPs and autonomy was assumed. While measures of trait autonomy exist (Bekker \& Assen, 2006; Weinstein, Przybylski, \& Ryan, 2012), no feasible measure was discovered to test the statistical significance of the relationship between SOPs and autonomy.

\section{Usability and the Technology Acceptance Model}

Usability is a concept that is encompassed by the broader term "user experience". User experience (UX) designers focus on having a deep understanding of users, their abilities, limitations, and their values, and implementing those factors into the products and 
interfaces which they design. Usability is a key measure which they consider during the development process. The official ISO 9241-11 definition of usability is: "the extent to which a product can be used by specified users to achieve specified goals with effectiveness, efficiency, and satisfaction in a specified context of use". One of the fundamental building blocks of usability is usefulness.

Usefulness and usability are nearly inextricable, and both have been tied to likelihood that any technology will be used at all. One model of this relationship is the technology acceptance model (TAM; Davis, 1989). The technology acceptance model is an information systems theory which models how users come to accept and use a technology. TAM initially considered two measures, perceived usefulness (PU) and perceived ease of use (PEOU). In accordance with flow theory, intrinsic motivation was recognized as a powerful motivator and subsequently joy, or perceived enjoyment (PE) was added to TAM (Venkatesh, 2000).

Lowry et al. (2012) further aligned flow theory and TAM. Working from the hedonicsystem acceptance model (Van der Heijden, 2004), a variant of TAM, Lowry et al. proposed to replace joy, or PE, with the construct of cognitive absorption (CA). Agarwal and Karahanna (2000) describe CA as a deep state of involvement with software systems stemming from intrinsic motivation. Generalize this information systems specific context and there is something very reminiscent of flow state. In accordance with the Landhäußer and Keller (2012) description of the components of flow, CA can be considered a secondorder construct encompassing several components of the flow experience (cf. Literature review, A). In theory, CA can also be considered similar to the flow short scale (FSS) through the subscale absorption by activity (Reinberg, Vollmeyer , \& Engeser, 2003). The 
Lowry et al. (2012) model was coined the hedonic-motivation system acceptance model (HMSAM). The work directly cites Csikszentmihalyi (1990) and Deci and Ryan (1985; 2000).

The work done by Lowry et al. (2012) creating HMSAM was crucial because it established a practical link between flow theory and usability, through the specific context of information systems. This thesis aimed to create a more general link between the experience of flow and the construct of usability as measured by the Computer System Usability Questionnaire (CSUQ; Appendix II; Lewis, 1995). Similar to the FSS, the CSUQ consists of 19 questions broken down into three subscales. Items 1-8 report system usefulness, items 9-15 report information quality, and items 16, 17, amd 18 report interface quality. Generating a preliminary relationship between the more general concepts of usability and flow theory could have tremendous implications in the way UX design is approached.

\section{State of Current Literature}

Overall, flow theory has been expanded on and connected to several theoretical bodies of work to include CET and variants of the TAM. Most of the experimentation in flow theory has been done to better understand how the state of flow arises, in hopes of better clarifying the edges of the theory in general. A literature review of flow research was published in 2012 by Stefan Engeser (Advances in Flow Research ). Many of this thesis' original ideas which were stimulated by reading Csikszentmihalyi's work directly (1990) became tangible through reading Engeser's collection of flow research in 2012. With all credit due to those who have done an excellent job defining, understanding, and connecting 
flow theory, there was a need for research on the applications of the principles of flow theory and their resulting consequences.

This work aimed to start laying the bricks on the foundation that has been built by Engeser and his colleagues. With the preconditions and components of flow being well understood, the consequences of this experiential state come to the forefront of this research. With the potential to hold the principles of flow theory as a paradigm from which to design any number of processes or interfaces, the possibilities are infinite. In more concrete terms, the field of Industrial Engineering will be better able to integrate humans and machines into socio-technical systems by leveraging a measurable understanding of how users are motivated to interact with and adopt technologies. Treating the operator as a user and designing for a user experience that facilitates flow could potentially have positive affect on a given process. 


\section{METHODOLOGY}

\section{A. Experimental Design}

The experimental design chosen is a two factor, $3 \times 2$ factorial between-subjects design (FIGURE 4). The two factors (independent variables), Design Prescription and Experience, have three levels and two levels, respectively. Design Prescription (Factor A) is leveled as open, prescribed, and over-prescribed. Experience (Factor B) is leveled beginner and advanced. Testing the interaction of each factor combination leaves a single replicate of six participants. Eight replicates are to be conducted resulting in 48 total participants. Two dependent variables will be measured: flow and usability. Usability will be measured by the CSUQ (Lewis, 1995) and flow will be measured by the FSS (Reinberg, Vollmeyer, \& Engeser, 2003).

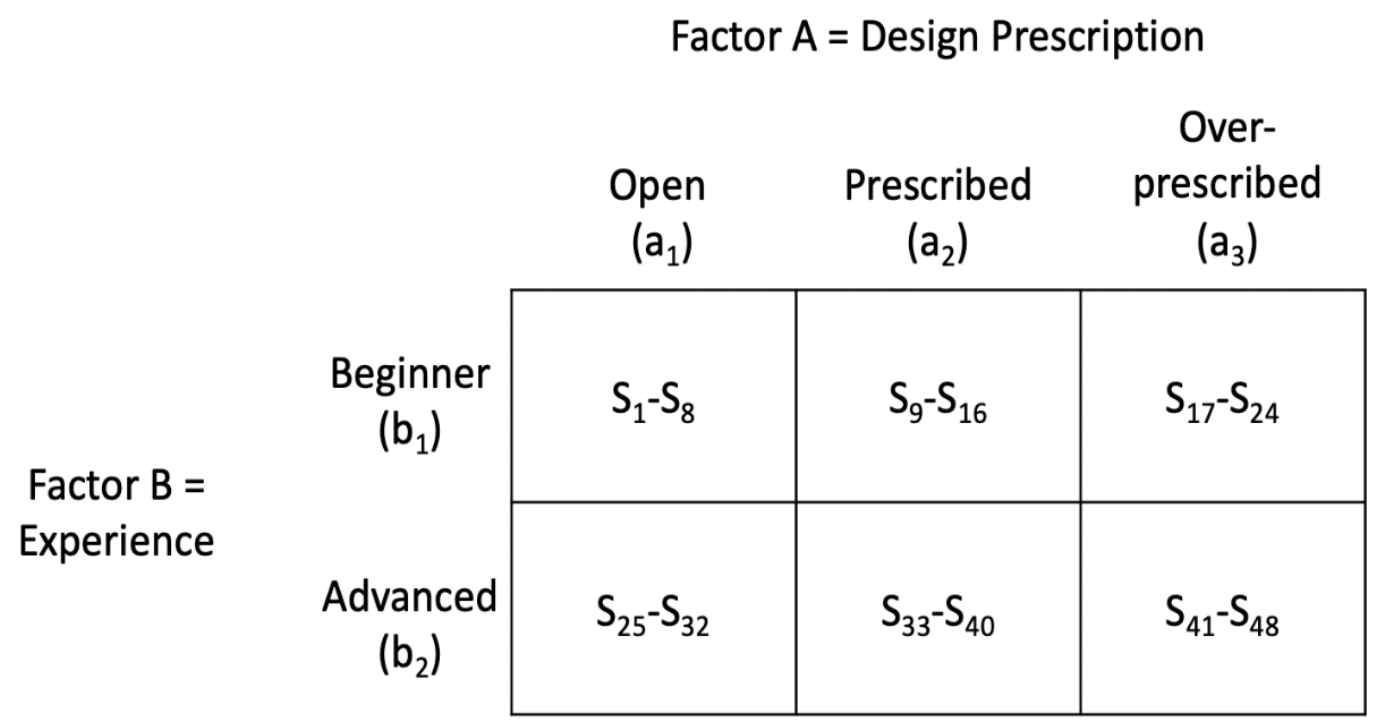

FIGURE 4 - Experimental Design 
All subjects regardless of Factor were provided with the same basic design parameters based on the design task described later in this chapter. The levels of Factor A, Design Prescription, were further defined as follows. Subjects given an open design were given the base design parameters and no further instruction, ultimately giving them free reign to approach modeling the design in any way they see fit (Appendix III). Subjects given prescribed design were provided with a standard operating procedure document that outlined the process from start to finish and gave general instructions on completing the model such as what SolidWorks tool to use for each step (Appendix IV). The final level of Design Prescription saw the subjects provided with an over-prescribed design (Appendix V). This was a separate standard operating procedure document which gave explicit stepby-step instructions on how to complete the modeling task such as "move to mouse to the sketch tool and left click".

The levels of Factor B, Experience, were further defined as follows. Beginners were students who were enrolled in ENGR 111 Engineering Methods, Tools and Practice II or ENGR 149 Introduction to Engineering Graphics, at the time of participation. There was a SolidWorks design project conducted in the class. Excluding any students with advanced SolidWorks experience, all students were acceptable candidates for the beginner level. Intermediate subjects were students who complete ENGR 150 Engineering Graphics Fundamentals or ENGR 151 Engineering Graphics Technology or ME 380 Computer Aided Design. Each of these classes expands on the fundamental knowledge previously gained in the earlier classes showing practiced fundamental knowledge and expansion into creative problem solving. The advanced group was anyone with greater experience than the two experience levels mentioned previously. The target population for the advanced 
group was anyone on engineering design teams at the University of Louisville, any graduate students working with SolidWorks modeling, and if necessary, recent graduates who use SolidWorks professionally.

\section{B. Participants}

The participants for this experiment were anticipated to be college aged students (minimum age 18 years). They were not restricted by department although it was anticipated that most would be from the Department of Mechanical Engineering. An attempt to test an equal number of males and females was made. Those with no prior experience with modeling in the SolidWorks software were excluded from participating in

the study. It was anticipated that participants from the beginner experience group would be younger on average than those in the intermediate and advanced experience groups (cf. Methodology, A).

\section{SolidWorks Software}

SolidWorks (Student Edition 2018-2019) is a 3D computer-aided design (CAD) software by Dassault Systèmes. SolidWorks leads the global 3D CAD industry with easyto-use 3D software that trains and supports the world's engineering and design teams as they drive tomorrow's product innovation (SolidWorks, n.d.). The program provides products and solutions in 3D CAD, simulation, product data management, electrical design, and much more (SolidWorks Products \& Solutions, n.d.). SolidWorks is used by students 
at the University of Louisville and therefore provides a subject base with a range of experience from which to draw. This software facilitated a computer-based modeling design task which was at the heart of the experiment analyzed in this thesis.

\section{Selection of Modeling Task}

A modeling design task to be completed in the SolidWorks computer-aided design software was selected as the task around which the experimental design would be centered. In order to choose an appropriate task, three factors were considered. These factors included projected time to complete task, relative task complexity, and previous exposure. For testing reasons, the desired task could not be largely time intensive and although the time to complete task would undoubtedly vary, the modeling design should take approximately 15-20 minutes to complete when tested on a low experience, prescribed design subject. The relative task complexity was driven by the time to complete consideration. Choosing a largely complex modeling task would alienate the lower experience levels and choosing a basic design task would not satisfy the preconditions of flow (cf. Literature Review, A). Finally, considering that with experience comes exposure to general modeling designs and exposure to the exact design task would muddy the experiment, a final modeling design was selected.

A spur gear was the designated modeling task. The given design parameters were the gear module and the number of teeth. This design task was chosen from learnsolidworks.com (Creating Spur and Helical Gears in SolidWorks, n.d.). The prescribed design for this task replicated the design found in this source. Ultimately, this 
task was chosen because it satisfies the three considered factors and provides enough alternate modeling approaches that prescriptive design was likely to limit the designer's creative liberty. Stated alternatively, subjects designing without prescriptive design were unlikely to design the model in the exact way that the prescriptive design described.

\section{E. Morae Software}

Morae software (Version 3.3.4) by TechSmith was used to capture quantifiable data for the study. Morae allows an experiment to set up, record, observe, and analyze usability studies, focus groups field research, and product testing (Morae, n.d.). Morae has three components: Morae Recorder, Morae Observer, and Morae Manager. Morae Recorder captures audio, video, on-screen activity, and keyboard/mouse input during a research session. Morae Observer enables team members to watch the subject's experience, make notes, and flag tasks in real time. Observer connects to the computer running Recorder via LAN/WAN/VPN. Morae Manager is used to view and analyze Morae recordings, automatically calculate metrics, generate graphs, and create highlight videos (Morae Components and Features, n.d.).

Morae was used as the medium through which directions and surveys were presented to the subjects. Through Morae Recorder, subjects were given instructions to guide them through the experiment. The program presented the subjects with the CSUQ (Lewis, 1995) and the FSS (Reinberg, Vollmeyer , \& Engeser, 2003) at the completion of their task and the data was recorded and accessed through Morae Manager. During the completion of the task, the subjects were monitored via Morae Observer and any necessary notes were taken. 


\section{F. Procedure}

The total experimental session was designed to last no longer than one hour. It consisted of several elements that are described in the remainder of the section. The next paragraph provides a timeline and description of the elements of the experimental session. The Center for Ergonomics Laboratory was able to facilitate the testing of up to two participants at a time. This was how participants were scheduled but based on availability a single participant could be tested as well.

At time $(\mathrm{t})=0$ the participants arrive at the Center for Ergonomics Laboratory. From $\mathrm{t}=0-5$ minutes, participants complete informed consent and are given an overview of the experiment. From $t=5-10$, participants are given up to 5 minutes to familiarize themselves with the layout of the SolidWorks software on the computer in the lab. During this time participants are free to model whatever they want or nothing at all; it is time wholly dedicated to familiarization. Participants are also informed to ask any questions that may arise. No changes to the interface may be made. At the end of the familiarization period from $\mathrm{t}=10-25$, participants complete the design task. If participants do not complete the design task in the 15 minutes allotted, they stop and save their work in its state at $\mathrm{t}=25$. From $t=25-30$, participants complete the CSUQ and FSS surveys through Morae (cf. Methodology, E). From $t=30-35$, participants are given 5 minutes of downtime where they can choose to do whatever they want: editing the design task, reading a magazine available at their desk, or doing nothing special at all. This follows Keller, Ringelhan, \& Blomann (2011), wherein $76 \%$ of participants who were given flow conditions chose to continue working on the experimental task (versus $39 \%$ and $54 \%$ in two non-flow conditions). Finally, from $t=35-45$, there is a 10 -minute debrief session during which 
the participants are interviewed about their experience with the experiment. The questions include:

- Based on the design task you just experienced with SolidWorks, would you have preferred a greater or lesser degree of design instructions? Or did the design instructions seem about right? Please explain.

- What did you think about the spur gear modeling task? That is, did you find it interesting?

- Did you feel like experience was a limiting factor in designing the gear? Would it have been easier with more experience?

- Did you feel like SolidWorks limited your ability to complete the design task? Would you have felt more focused if using another program?

The participants are also given a form that describes the purpose of the study, allows for confidentiality concerns to be addressed, gives contact information, a reference list for further reading, and the option to request the final report or summary of results from the study.

Once a participant leaves the lab, the experimenter has 5-10 minutes to secure the data and reset the testing environment for the next participant. During this time, any necessary notes can be synthesized, and any personal maintenance can be conducted.

\section{G. Analysis}

Analysis of Variance (ANOVA) was planned to test for a main effect of Design Prescription and Experience on flow and usability, as well as reveal a potential interaction effect between Design Prescription and Experience. For any main effect discovered, post- 
hoc analysis was planned to isolate the significant difference(s) among level of that independent variable. A potential interaction between Design Prescription and Experience was to be analyzed using graphing procedures or a simple-effects test to determine significant change in one factor at each level of the other factor. A binary logistic regression was to be used to analyze the relationship between flow and how the participants acted during the period of downtime. Finally, a potential relationship between flow and usability was examined using a Spearman rank-order correlation coefficient, or other appropriate test for measuring the strength between two dependent variables measured on an ordinal scale. A significance level of .05 was used for all statistical tests. 


\section{AMENDMENTS}

The collection of data for this study began 21 February 2020. Within three weeks following the start of this study, the landscape of the entire world shifted drastically. The global COVID-19 pandemic sent our institutions as a nation and as a global society into unprecedented areas of government and livelihood. During the time leading up to the implementation of social distancing and the subsequent shut down of all non-essential research at most universities, recruitment of participants for this study was proceeding. After discussion with the director of this thesis committee pivots were made which effected (1) the experimental design of this study and subsequently the type of analysis to be done, (2) one of the three hypotheses offered, and (3) the exclusion criteria for the participants. Each of these changes are discussed in detail in the following sections.

\section{A. Experimental Design and Analysis}

The original experimental design chosen is a two factor, $3 \times 2$ factorial betweensubjects design (FIGURE 4). The two factors (independent variables), Design Prescription and Experience, have three levels and two levels, respectively. Design Prescription (Factor A) was leveled as open, prescribed, and over-prescribed. Experience (Factor B) was leveled beginner and advanced.

The newly adopted experimental design is a one factor, $1 \times 2$ factorial between-subjects design (FIGURE 5). Each replicate contains two participants. Eight replicates were completed to result in 16 total participants. 


\section{Factor $\mathrm{A}=$ Design Prescription}

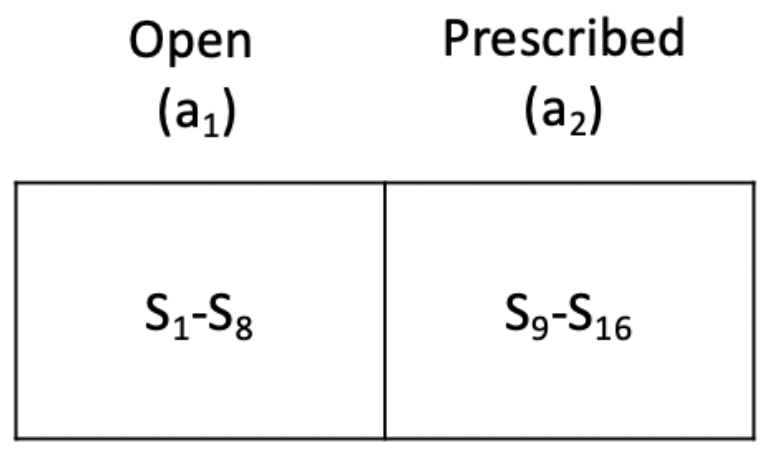

FIGURE 5 - Newly Adopted Experimental Design

The factor of Experience was initially eliminated to ease the shortcomings of the recruitment efforts. This took the total number of participants and halved it from 48 to 24 . Once the pandemic struck the nation and measures were starting to be taken to stifle the spread of the virus, a tactical pivot was made to condense Design Prescription from three levels (open, prescribed, over-prescribed) to two (open, prescribed). This would allow both prescribed and overprescribed to be combined into the new prescribed level. The new Design Prescription factor thus measures the effects of limited design prescription versus any design prescription on the flow experience.

At the time of the changes due to the novel coronavirus that caused the global COVID-19 crisis, $\mathrm{n}=11$ participants had already been tested under the previous experimental design. Figures 6 and 7 show how the participants fell in the previous experimental design matrix and how they were adapted to the new matrix. Figure 8 Shows how the final $n=16$ participants would have fallen in the original experimental design. 


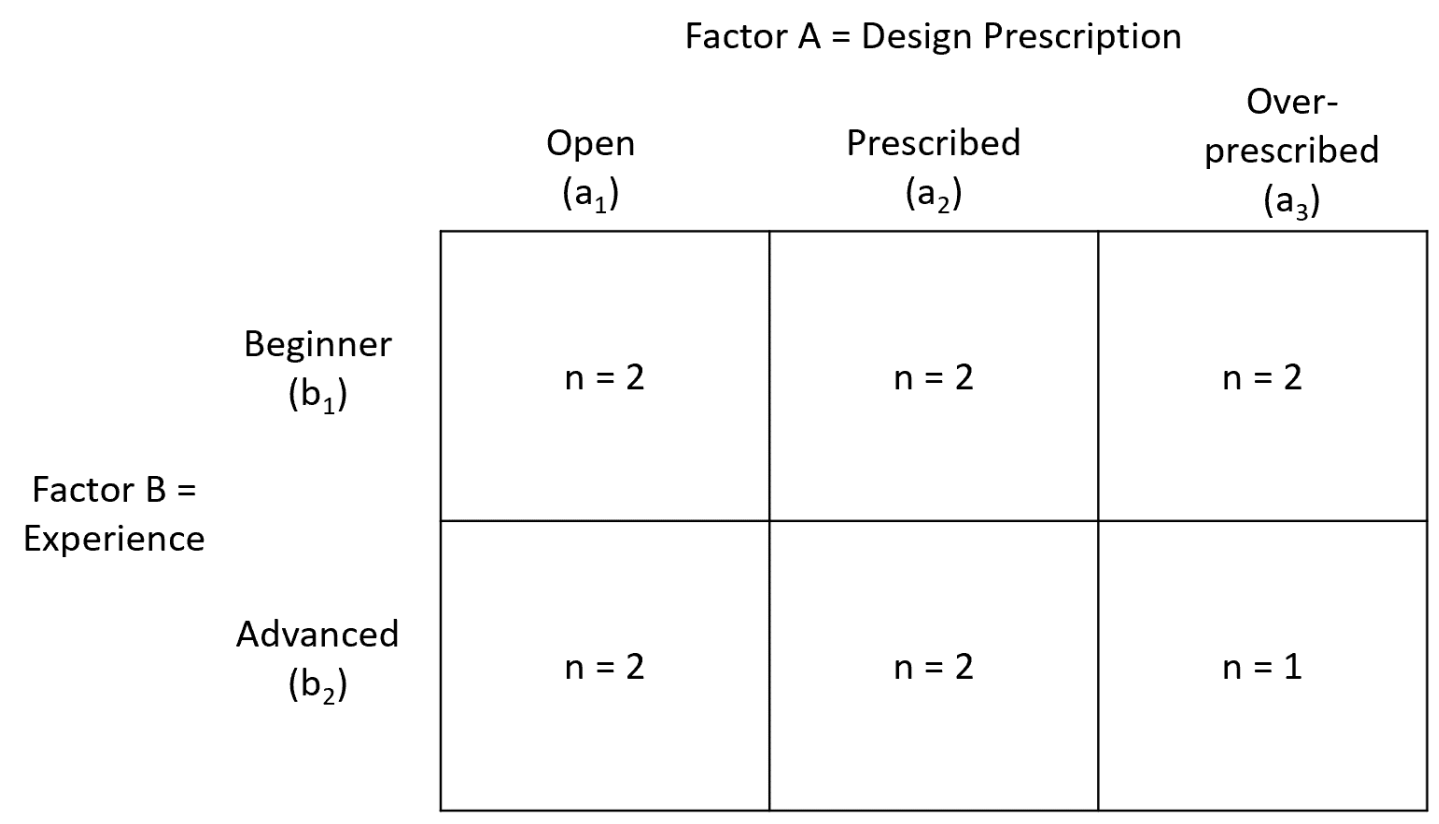

FIGURE 6 - N = 11 Participants Tested Before Amendments

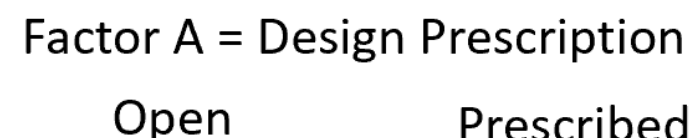

$\left(a_{1}\right)$

$\left(a_{2}\right)$

\begin{tabular}{|l|l|}
\hline$n=4$ & $n=7$ \\
& \\
\hline
\end{tabular}

FIGURE $7-\mathrm{N}=11$ Participants Adapted to New Experimental Design 


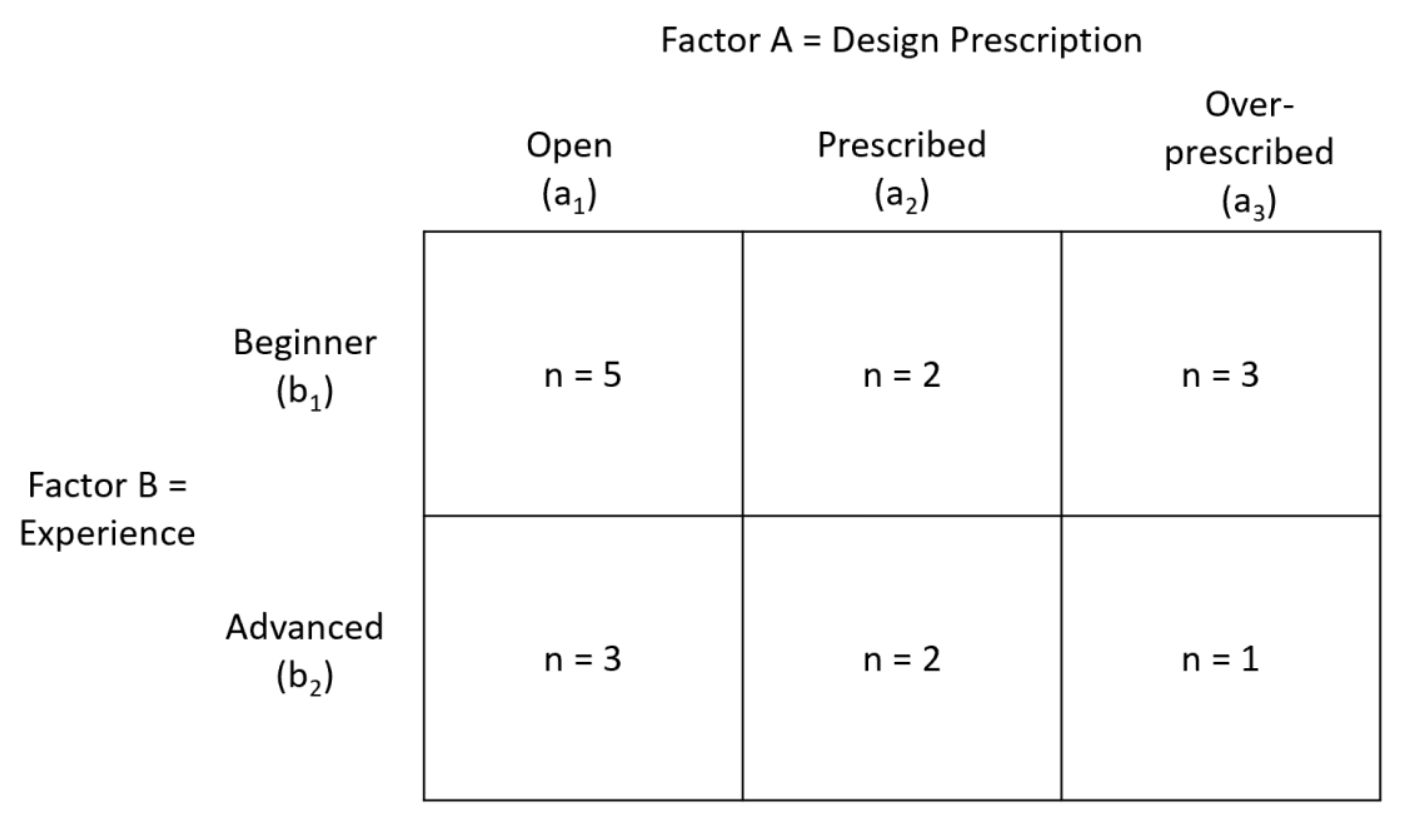

FIGURE 8 - N = 16 Participants if Original Experimental Design Used

The simplification of the experimental design also led to a simplified analysis strategy for the data. Data was collected on two surveys, the Flow Short Scale (FSS; Appendix III) and the Computer System Usability Questionnaire (CSUQ; Appendix IV). The FSS consisted of 13 questions on a 7-point Likert scale broken up into 3 subscales: (1) fluency of performance (FP; items 2, 4, 5, 7, 8, 9), (2) absorption by activity (AA; items 1, 3, 6, 10), and (3) perceived importance (PI; items 11, 12, 13). Three addition items, demand, skills, and the perceived fit of demands and skills were measured on a 9-point Likert scale (items 14, 15, 16). The CSUQ consisted of 19 questions on a 7-point Likert scale broken up into 3 subscales: (1) system usefulness (SU; items 1-8), (2) Information Quality (InfoQ; items 9-15), and (3) Interface Quality (InterQ; items 16-18). Two statistical tests were conducted with the survey data collected form the lab experiment, a two-sample t-test and Spearman's rank order coefficient, which was used to determine the correlation between 
the ordinal scales. A test for normality was also run do determine if the use of a nonparametric Mann-Whitney test was more appropriately used.

\section{B. Hypotheses}

The newly adopted experimental design explained in the previous section forces a limitation on to the hypotheses presented earlier in this work. With the elimination of the experimental factor Experience, the data will no longer provide any information regarding the second research question "How does the interaction between experience and design affect flow?" or its related hypothesis. Therefore, going forward two hypotheses were tested where hypotheses 1 and 3 were tested as previously described and hypothesis 2 was eliminated entirely. These hypotheses were amended to be as follows:

- What type of design task is more likely to elicit flow state?"

Hypothesis 1: Subjects presented with an open design will be more likely to report flow than subjects presented with prescriptive design.

- "How does the interaction between experience and design task affect flow?" Hypothesis 2: An inverse relationship will be present showing less experienced subjects experiencing flow with more prescriptive design and more experienced subjects experiencing flow with less prescriptive design.

- "What is the relationship, if any, between product usability and the ability of a user to achieve flow state?"

Hypothesis 2: Users who report high usability while interacting with a product, as measured by the CSUQ, are more likely to report experiencing 
flow. A significant difference in Flow Short Scale scores would indicate a difference in the flow experience.

\section{Exclusion Criteria}

The final area affected by the recruitment challenges and subsequent global pandemic was a relaxing of the exclusion criteria in order to bolster recruitment efforts. The exclusion criteria of having no previous experience with the SolidWorks program was relaxed and two participants with no prior experience were tested. This lack of experience was mitigated slightly by having the participants download SolidWorks on their personal computers and completing the included tutorials before entering the lab to be tested. This was done so that their exposure to the user interface was not entirely novel upon their participation in the experiment. 


\section{RESULTS}

The study was conducted with $n=16$ participants. Six of participants were aged 18 20, four were aged 21-23, four were aged $24-26$, and two were aged $>26$. Of the 16 participants, seven were female and nine were male. All participants were racially white, and one was ethnically Hispanic. One participant self-reported autism. There was little difference between those participants recruited as beginner and those recruited as advanced (ref. FIGURE 6). There were two participants in the study who, in hindsight, can be considered advanced, other than those two, the rest were undoubtedly novice, beginner, or intermediate The pie chart (FIGURE 7) with results of 16 participants self-reported years of experience using SolidWorks showed 2 (12.5\%) participants had >3 years (the same two with $4 / 5$ rating from figure 6$)$ and $3(18.8 \%)$ reported 1-2 years. This clearly shows there was not enough differentiation in experience to include a meaningful experience factor.

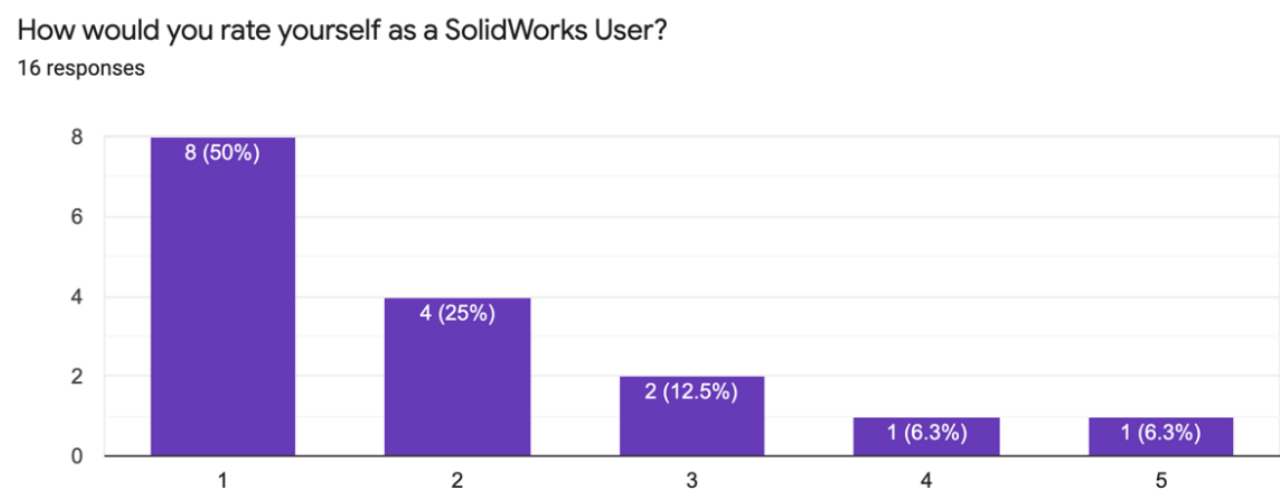

FIGURE 9 - SolidWorks Self-Rating Results

Note: On the 1-5 scale, 1 represents Novice and 5 represents Expert 
How many years of experience do you have using SolidWorks?

16 responses

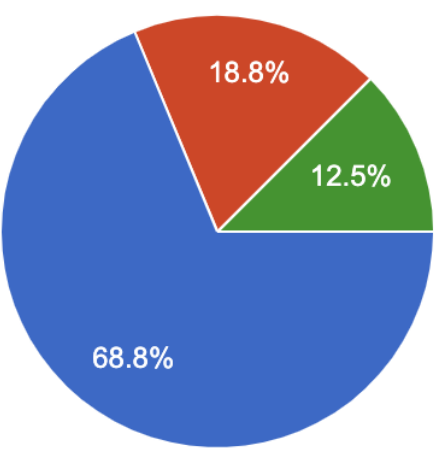

$<1$ year

1-2 years

2-3 years

$>3$ years

FIGURE 10 - SolidWorks Experience Pie Chart

\section{A. Two-Sample T-Test}

The scores for the items in each survey were averaged across each participant survey subscales as well as averaged for an overall survey score. These data were then averaged to determine the average response across each factor level (open, prescribed; see Figures $8,9)$. Note that in figures 8 and 9 , a higher score is correlated with a higher perception of flow or usability. A test for normality was conducted to determine if a non-parametric Mann-Whitney test would be necessary; all data tested were normally distributed with a 95\% confidence interval (TABLE 1). Note that if the confidence interval was relaxed to 90\%, both FP and FSS in the Open category fail the test for normality. A two-sample t-test with a 95\% confidence interval was used to determine if there was a significant different between the means of like subscales in the open versus prescribed (Rx) design categories (TABLE 2, 3). Equal variances were not assumed for this analysis. 
TABLE 1

NORMALITY TEST BY SUBSCALE

\begin{tabular}{|c|c|c|c|}
\hline \multicolumn{5}{|c|}{ Normality Test } \\
\hline Open & P-Value & Rx & P-Value \\
\hline FP & 0.091 & FP & 0.889 \\
\hline AA & 0.653 & AA & 0.917 \\
\hline PI & 0.589 & PI & 0.349 \\
\hline FSS & 0.053 & FSS & 0.978 \\
\hline SU & 0.118 & SU & 0.323 \\
\hline InfoQ & 0.412 & InfoQ & 0.094 \\
\hline InterQ & 0.699 & InterQ & 0.353 \\
\hline & 0.205 & CSUQ & 0.490 \\
\hline & & & \\
\hline & & & \\
\hline CSUQ & & & \\
\hline & & & \\
\hline
\end{tabular}




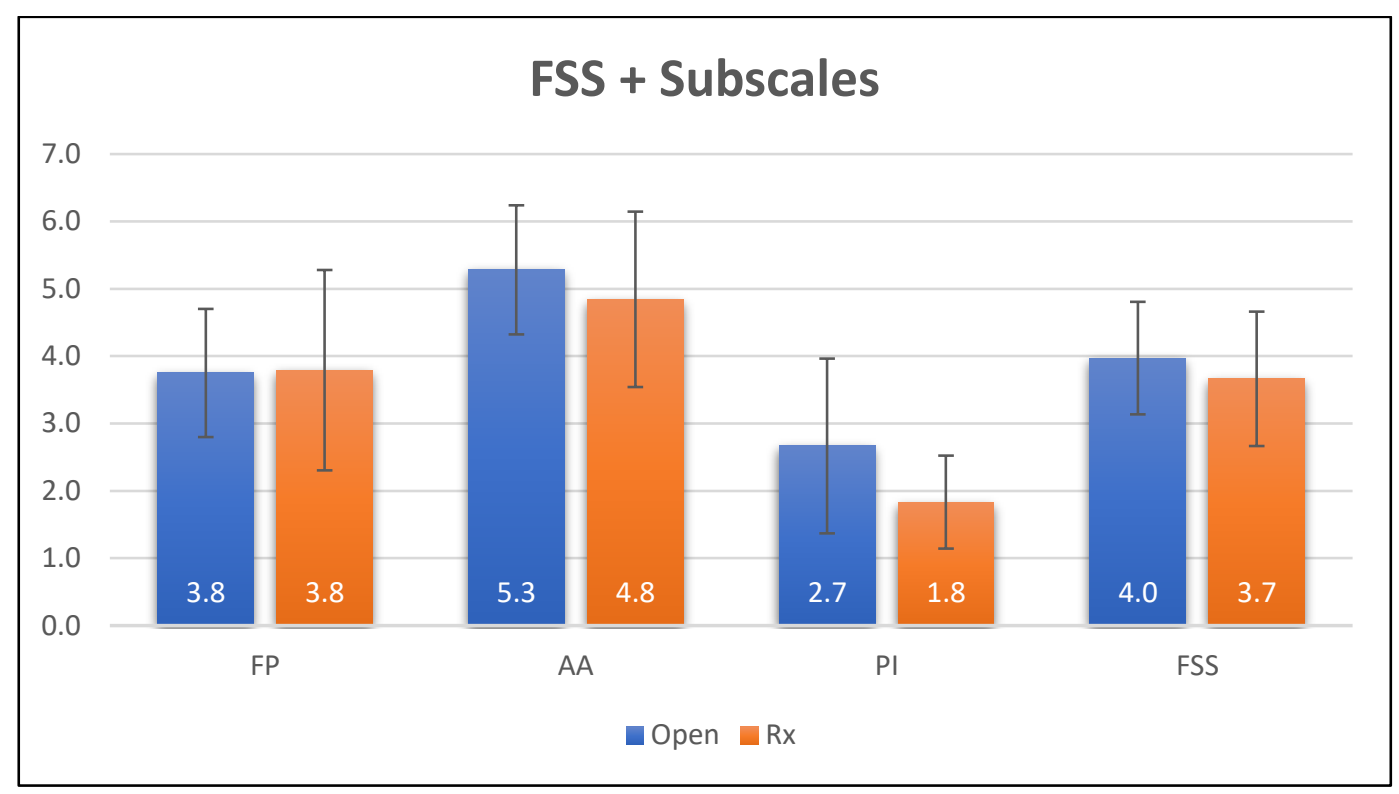

FIGURE 11 - FSS and Subscales Means

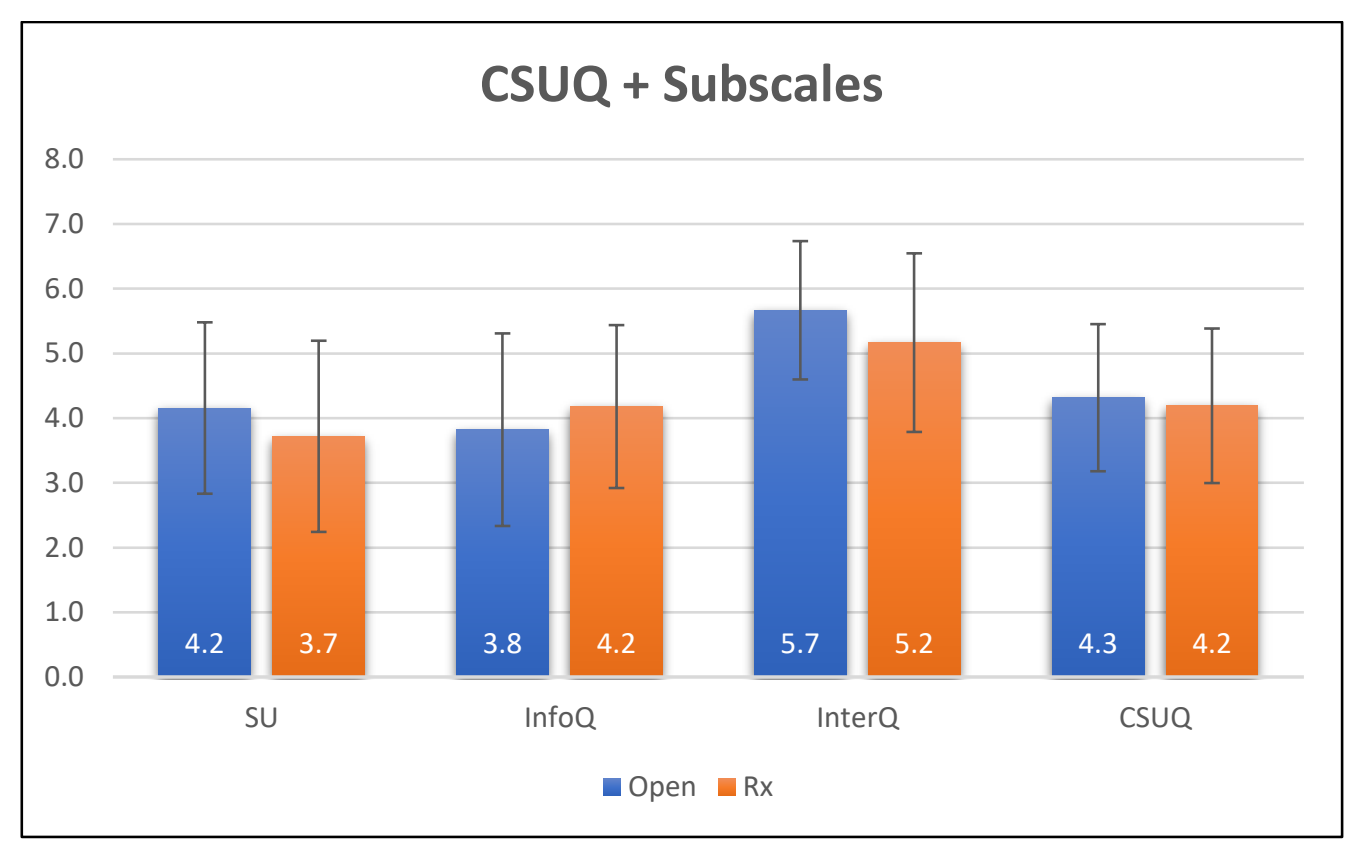

FIGURE 12 - CSUQ and Subscales Means 
TABLE 2

FSS TWO-SAMPLE T-TEST RESULTS

\begin{tabular}{|c|c|c|c|c|c|c|}
\cline { 2 - 7 } \multicolumn{1}{|c|}{} & \multicolumn{6}{|c|}{ Two-Sample T-Test } \\
\hline \multirow{3}{*}{$\approx$} & $\mu_{1}$ & $\mu_{2}$ & T-Statistic & Mean(SD)-Open & Mean(SD)-Rx & P-Value \\
\cline { 2 - 7 } & FP-Open & FP-Rx & -0.07 & $3.75(0.95)$ & $3.79(1.49)$ & 0.948 \\
\cline { 2 - 7 } & AA-Open & AA-Rx & 0.77 & $5.28(0.96)$ & $4.84(1.30)$ & 0.459 \\
\cline { 2 - 7 } & PI-Open & PI-Rx & 1.60 & $2.67(1.30)$ & $1.83(0.69)$ & 0.140 \\
\cline { 2 - 7 } & FSS-Open & FSS-RX & 0.67 & $3.97(0.84)$ & $3.66(1.00)$ & 0.515 \\
\hline
\end{tabular}

Note: Null hypothesis $H_{0}: \mu_{1}-\mu_{2}=0$; Alternative hypothesis $H_{1}: \mu_{1}-\mu_{2} \neq 0$.

TABLE 3

CSUQ TWO-SAMPLE T-TEST RESULTS

\begin{tabular}{|c|c|c|c|c|c|c|}
\cline { 2 - 7 } \multicolumn{1}{c|}{} & \multicolumn{6}{c|}{ Two-Sample T-Test } \\
\hline \multirow{3}{*}{} & $\mu_{1}$ & $\mu_{2}$ & T-Statistic & Mean(SD)-Open & Mean(SD)-Rx & P-Value \\
\cline { 2 - 7 } & SU-Open & SU-Rx & 0.62 & $4.16(1.32)$ & $3.72(1.48)$ & 0.544 \\
\cline { 2 - 7 } & InfoQ-Open & InfoQ-Rx & -0.52 & $3.82(1.49)$ & $4.18(0.45)$ & 0.613 \\
\cline { 2 - 7 } & InterQ-Open & InterQ-Rx & 0.81 & $5.67(1.07)$ & $5.17(1.38)$ & 0.432 \\
\cline { 2 - 7 } & CSUQ-Open & CSUQ-Rx & 0.21 & $4.32(1.14)$ & $4.19(1.19)$ & 0.834 \\
\hline
\end{tabular}


No statistically significant findings were revealed during this analysis. Two of the eight participants in the Open design category were the two participants who were previously mentioned to be considered advanced. The normality test and subsequent analyses were run excluding these two participants resulting in no difference to the normality under a $90 \%$ confidence interval. Therefore, the inclusion of the two "advanced" participants in the Open design did not skew the results in any way. Regarding the two elements, FSS and FP which were abnormal with a 90\% confidence interval, a Mann-Whitney test was conducted and resulted in no significant differences between the means.

Regarding the first hypothesis of this thesis, note that overall FSS score comparison resulted in a $p$-value $=0.515$ for FSS-Open versus FSS-Rx. This fails to reject the null hypothesis with P > .05 therefore does not support thesis hypothesis 1.

- "What type of design task is more likely to elicit flow state?"

Hypothesis 1: Subjects presented with an open design will be more likely to report flow than subjects presented with prescriptive design.

\section{B. Spearman's Rank Order Coefficient}

Regarding the second hypothesis of this thesis, a Spearman's rank order coefficient was determined for every combination of scales and subscales. Tables 4,5 hold the results of the data for the Open and Rx categories, respectively. The tables have been formatted such that the darker colors have a more positive correlation and the lighter colors a more negative correlation with +1 being a perfectly positive correlation and -1 being a perfectly negative correlation. 
TABLE 4

SPEARMAN'S RANK ORDER COEFFICIENTS FOR OPEN DESIGN

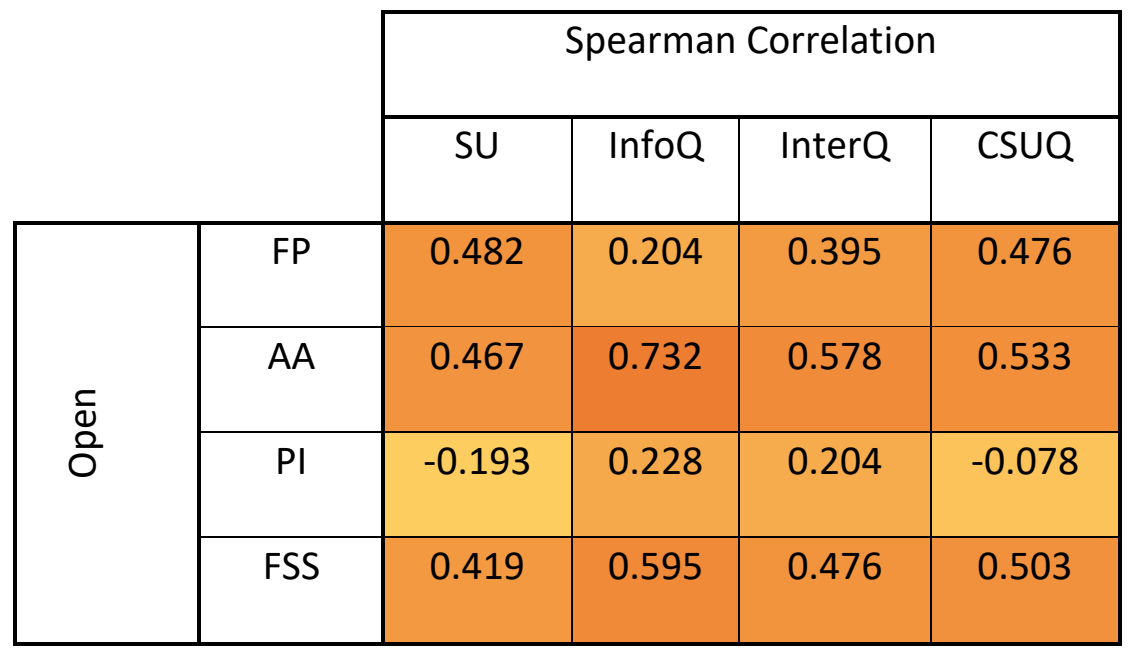

TABLE 5

SPEARMAN'S RANK ORDER COEFFICIENTS FOR PRESCRIBED DESIGN

\begin{tabular}{|c|c|c|c|c|c|}
\cline { 3 - 6 } \multicolumn{2}{c|}{} & \multicolumn{4}{c|}{ Spearman Correlation } \\
\cline { 3 - 6 } \multicolumn{2}{c|}{} & SU & InfoQ & InterQ & CSUQ \\
\hline \multirow{3}{*}{$\times$} & FP & 0.608 & 0.132 & 0.343 & 0.228 \\
\cline { 2 - 6 } & AA & 0.503 & -0.095 & -0.036 & -0.048 \\
\cline { 2 - 6 } & PI & -0.333 & 0.036 & -0.303 & -0.181 \\
\cline { 2 - 6 } & FSS & 0.599 & 0.119 & 0.168 & 0.143 \\
\hline
\end{tabular}


Regarding the second hypothesis, note that the FSS to CSUQ Spearman correlation coefficient of $r=0.503$ for the Open design and $r=0.143$ for the prescribed design does not support hypothesis 2 :

- "What is the relationship, if any, between product usability and the ability of a user to achieve flow state?"

Hypothesis 2: Users who report high usability while interacting with a product, as measured by the CSUQ, are more likely to report experiencing flow. A significant difference in Flow Short Scale scores would indicate a difference in the flow experience.

\section{Skill v. Challenge}

The last three items on the FSS provide a direct plot on Csikszentmihalyi's original flow model (FIGURE 1). The resulting figure shows that most participants perceived the demands to be too high for their skills, placing themselves in the anxiety category (FIGURE 10). Figure 10 should be used in conjunction with Figure 11 which shows the perceived fit of skills and demands based on the final additional item on the FSS. The

question asks, "For me personally, the current demands are..." and is measure on a 9-point Likert scale where 1 represent "too low", 9 represent, "too high", and 5 represent "just right". 


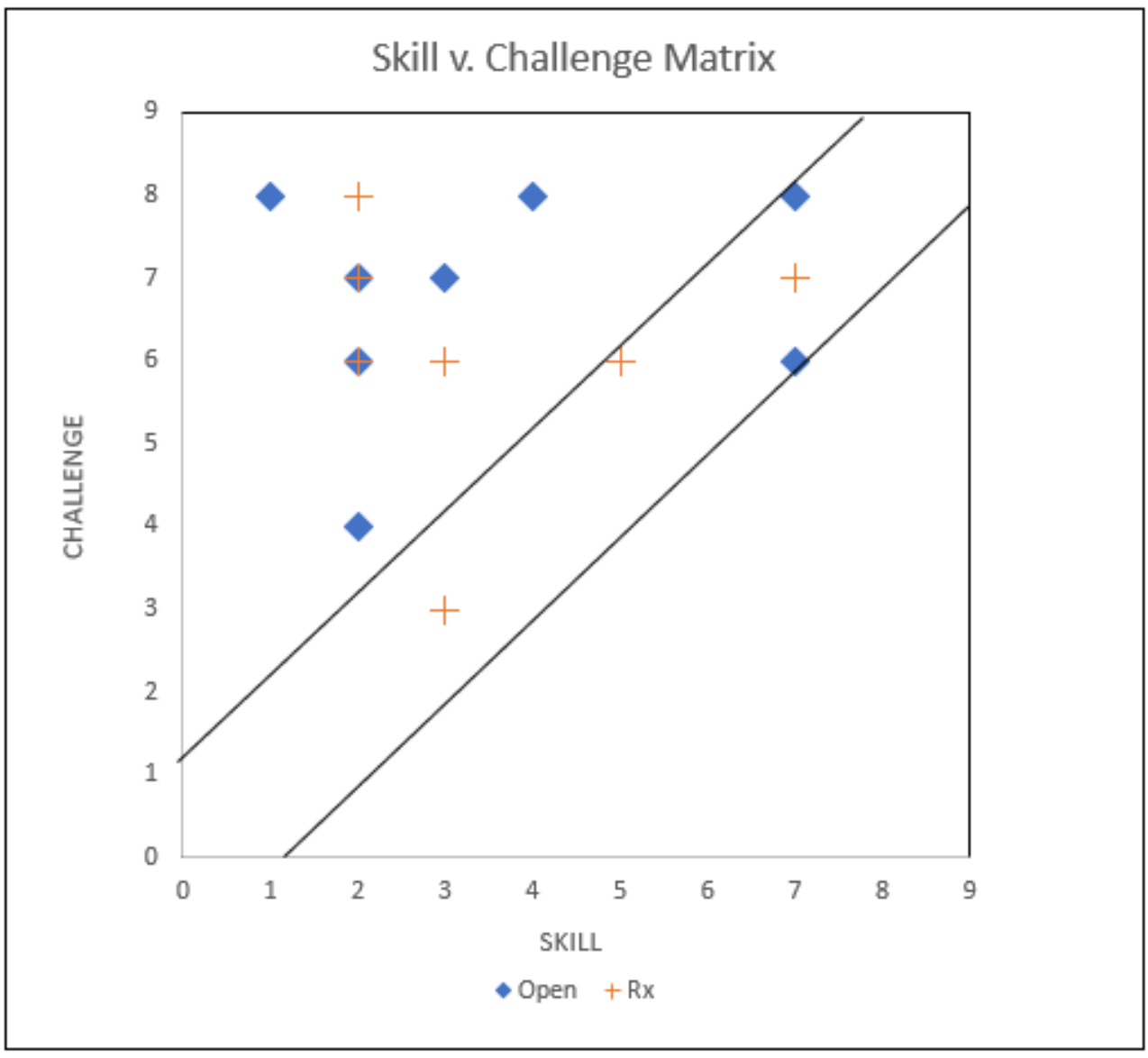

FIGURE 13 - Original Flow Model with Participant Response Plotted

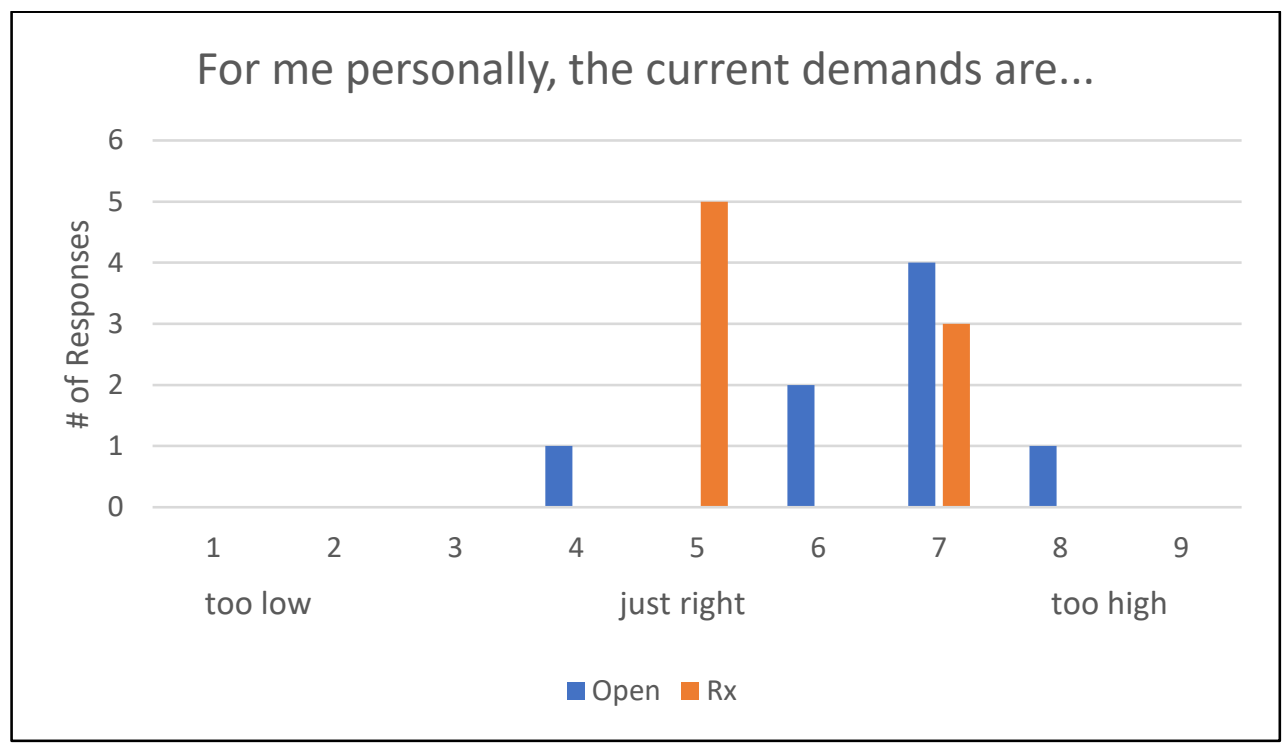

FIGURE 14 - Response to FSS Item 16 


\section{Exit Interviews}

The following are the tabulated responses for the exit interviews. They have been categorized by the most common response to each question. The quantity of participants which gave each response are listed by which design prescription they were given.

TABLE 6

\section{EXIT INTERVIEW QUESTION 1}

Based on the design task you just experienced with SolidWorks, would you have preferred a greater or lesser degree of design instructions? Or did the design instructions seem about right? Please explain.

\begin{tabular}{|c|c|c|c|c|c|c|}
\hline Response & \multicolumn{2}{|c|}{ Greater } & \multicolumn{2}{c|}{ About Right } & \multicolumn{2}{c|}{ Different } \\
\hline Design Prescription & Open & Rx & Open & Rx & Open & Rx \\
\hline Number of Responses & $\mathrm{n}=4$ & $\mathrm{n}=2$ & $\mathrm{n}=3$ & $\mathrm{n}=4$ & $\mathrm{n}=1$ & $\mathrm{n}=2$ \\
\hline
\end{tabular}

TABLE 7

EXIT INTERVIEW QUESTION 2

Did you feel like experience was a limiting factor in designing the gear? Would it have been easier with more experience?

\begin{tabular}{|c|c|c|c|c|}
\hline Response & \multicolumn{2}{|c|}{ Yes } & \multicolumn{2}{c|}{ No } \\
\hline Design Prescription & Open & $\mathrm{Rx}$ & Open & $\mathrm{Rx}$ \\
\hline Number of Responses & $\mathrm{n}=7$ & $\mathrm{n}=5$ & $\mathrm{n}=1$ & $\mathrm{n}=3$ \\
\hline
\end{tabular}


TABLE 8

\section{EXIT INTERVIEW QUESTION 3}

What did you think about the spur gear modeling task? That is, did you find it interesting?

\begin{tabular}{|c|c|c|c|c|}
\hline Response & \multicolumn{2}{|c|}{ Interesting } & \multicolumn{2}{c|}{ Indifferent } \\
\hline Design Prescription & Open & $\mathrm{Rx}$ & Open & $\mathrm{Rx}$ \\
\hline Number of Responses & $\mathrm{n}=8$ & $\mathrm{n}=5$ & $\mathrm{n}=0$ & $\mathrm{n}=3$ \\
\hline
\end{tabular}

TABLE 9

\section{EXIT INTERVIEW QUESTION 4}

Did you feel like SolidWorks limited your ability to complete the design task? Would you have felt more focused if using another program?

\begin{tabular}{|c|c|c|c|c|}
\hline Response & \multicolumn{2}{|c|}{ Yes } & \multicolumn{2}{c|}{ No } \\
\hline Design Prescription & Open & $\mathrm{Rx}$ & Open & $\mathrm{Rx}$ \\
\hline Number of Responses & $\mathrm{n}=0$ & $\mathrm{n}=2$ & $\mathrm{n}=8$ & $\mathrm{n}=6$ \\
\hline
\end{tabular}

\section{E. Continued Work}

Previously mentioned in section III, the participants were given five minutes after they completed the FSS and CSUQ to do whatever they would like while still in the testing area. This included working on the model again even though their task was complete. This was inspired by Keller , Ringelhan, \& Blomann (2011). A table showing how many paricipants in each design prescription group decided to work again (TABLE 10) and a figure showing the FSS and its subscales for those who chose to work again and chose not to work again (FIGURE 15) were created to display the data collected during the study. 
Table 10

DID/DID NOT WORK AGAIN

\begin{tabular}{|c|c|c|}
\cline { 2 - 3 } \multicolumn{1}{c|}{} & Open & Prescribed \\
\hline Did Work Again & $\mathrm{n}=5$ & $\mathrm{n}=2$ \\
\hline Did Not Work Again & $\mathrm{n}=3$ & $\mathrm{n}=6$ \\
\hline
\end{tabular}

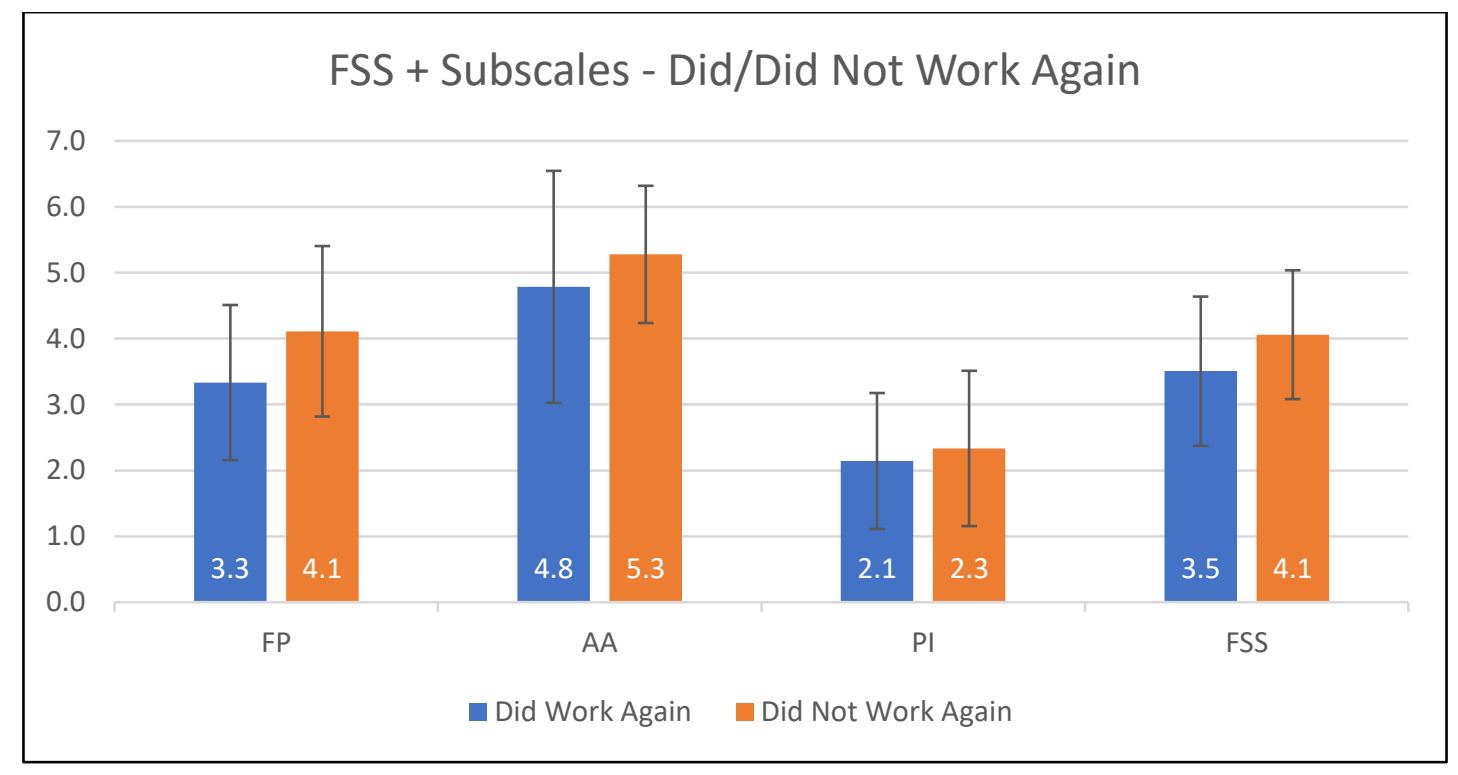

FIGURE 15 - FSS + Subscale - Did/Did Not Work Again 


\section{DISCUSSION}

The following section contains a discussion based around several aspects of the study. The first section discusses implications of the data reported in the results section. The second section discusses the skill v. challenge model of flow presented by Csikszentmihalyi (1975). The third section discusses the subjective findings from the exit interviews conducted with all study participants. The fourth and final section is a general discussion covering any information and ideas that could not be discussed in the previous three sections.

\section{A. Interpretation of Results}

Regarding the results of the statistical analyses reported in the previous section (Section V), there are several findings that are noteworthy. What should be brought to the forefront of attention first is that the lack of statistically significant findings can perhaps be partially attributed to the small sample-size of $n=16$. Alternatively, this could be a result of condensing all experience levels into one group. It should be noted that both of the "truly" advanced users were part of the Open category. The circumstances surrounding the data collection during this study have been discussed in section IV, and it should be noted that some of the following discussion is speculative.

Potentially promising findings arise when looking at the mean and $p$-value for PI on the FSS. The mean score for PI-Open was 2.7 versus the mean score for PI-Rx of 1.8. A 1-point difference on a 7-point Likert scale represented by $p$-value $=0.140$ could be brought to greater prominence with a larger sample size. The potential implications of this 
finding are that participants given no design instruction could be more likely to perceive their work as important when compared to those who are given design instruction. This is consistent with Cognitive Evaluation Theory by Deci and Ryan (1985). The perceived autonomy of the subject could give them greater ownership over their work hence making it more important to them. It could also be true that greater ownership measured by perceived importance could result in improvements in overall quality of work; this is a possibility and must be studied more to determine a meaningful relationship.

The findings of the Spearman correlation analysis can be summarized by saying the greatest correlation was seen between AA and InfoQ in the open design category with $r=$ 0.732. This means there is a relatively high positive correlation between the average response on self-reported task absorption and the perceived quality of information in the system. In other words, if one perceives the quality of information in a system to be high, they are likely to be highly absorbed by their activity. This should be intuitive since high quality information in a system serves to satisfy the prerequisites for the flow experience to arise, namely clear goals and clear feedback (cf. section II A). Several other coefficients of $r>0.500$ appear such as average FSS score and information quality in the Open design category $(r=0.595)$, average FSS score to overall system usefulness $(r=0.599)$, and average perceived fluency of performance to overall system usefulness $(r=0.608)$ for the Rx category.

These data show potential associations and should be interpreted considering the small sample size collected. More information can be gained as much of the Open design table shows correlation coefficients of $r>0.500$ which could be amplified with a larger sample size. Although the means of the CSUQ and subscales were not significantly different from 
open to Rx, it is interesting to note that several of the correlation coefficients on the Rx table are either close to $r=0$ or slightly negative. This seems to speak to a difference in how Open and Rx design relate to the usability of a system. While this data does not declare a highly positive correlation between FSS score and CSUQ score, it can be deduced that a potential relationship exists between reported flow experience and the perceived usability of system.

\section{B. Skills v. Challenge and Continued Work}

Regarding Figure 10 from the section V, although this flow model is antiquated, it still gives a good perspective for how the participants perceived their flow experience. It should be noted that there are several factors at play which were not considered in the statistical analysis. There is a possibility that the time constraint given could be another reason why there is little difference between groups. Also, several participants reported the Center for Ergonomics was hard to find or it was their first time in the building. It is possible that stressors such as these could have limited the overall flow experienced by the subjects. It is also true that one of the three preconditions for the flow experience as discussed in section II A is skills and demands that are in balance. Therefore, this graph could be a powerful indicator of the effectiveness of a work system. Understanding where a workforce feels the demands are with respect to their skills could not improve their overall work experience but give good insight into necessary engineering changes that need to be made. For example, since most of the data resides in the low skill, high demand 
region of anxiety, an engineer may seek to take one of two actions: increase the skill of the workforce or decrease the task demands.

Note that this is an approximate form of measurement and there are two subjects who were part of the Rx design that reported an equal skill challenge balance prescription category according to the model. The other three subjects on the edge of the skill demand channel were two from the open category and one form the Rx category.

Regarding Figure 11, more than half $(n=5)$ of the Rx reported a 5 while $n=7$ from the Open group reported $>5$. This makes logical sense due to the Open group having been given minimal instruction to complete the design task, hence elevating the challenge. Considering this in combination with the relative similarity in experience between all participants, it is logical to assume that the Rx group would perceive a better skill challenge balance with both groups having similar skills and one group (Open) having a greater challenge. Ultimately, a factor concerning experience would possibly be able to elucidate this relationship.

Regarding the results section F. Continued Work, it is very interesting to see that although more participants from the Open category continued to work $(n=5)$ than from the Prescribed category $(n=2)$, those who chose to work again averaged a lower score one every FSS subscale and on overall flow. It is consistent with the thoughts in this thesis that those from the Open design category would be more likely to continue working on the task. It was anticipated that this would be as a result of those participants feeling more autonomy and therefore flow. This was not the case. It could be that since those in the Prescribed design category had a set of steps laid out for them, the curiosity or pursuit of the next steps in their mind was not present. It is possible that those from the Open design who continued 
working on the task had next steps in mind which they could not get to due to the time constraint. Since these procedures were autonomous, it is possible that they cared more to see them through even though their task was complete, and they were told to spend the five minutes however they pleased.

\section{Exit Interviews}

An exit interview consisting of four questions was conducted with all participants after the completion of the experimental design task. Question one asked about the amount of design instruction desired versus what the participant was given. Question two asked if the participant found the modeling task to be interesting. Question three asked if the participant felt that experience was a limiting factor. Question four asked if the participant felt that SolidWorks limited their ability to complete the design task.

- Based on the design task you just experienced with SolidWorks, would you have preferred a greater or lesser degree of design instructions? Or did the design instructions seem about right? Please explain.

The most common response for this question was "greater", with seven participants giving this answer. The most common explanation for why a greater degree of design instruction was desired cited a lack of experience. The second most common response saw six participants say the amount of design instruction they received was right or about right. The most interesting explanation combined with this response came from a participant in the open category who said, "it was fun to do the trial and error process". Based on this participant's responses and general interaction with the experiment, it is safe to say that the participant had a particularly autotelic personality. It should be noted that the FSS score 
for this participant fell on the mean of the FSS responses in the open category. The final type of response to question one was from two participants who wanted neither more nor less instruction but "different". I found this to be an interesting response as one participant was from the open category and one from the Rx. Ultimately, this question was greatly intertwined with the experience and perceived competence of each participant.

- Did you feel like experience was a limiting factor in designing the gear? Would it have been easier with more experience?

When asked whether experience was a limiting factor in the design modeling task twelve participants responded with yes, seven from the Open category and five from the Prescribed category. Many of the participants had limited experience using SolidWorks so this was expected. The second most experienced participant was also a part of the "yes" respondents saying, "CAD modeling is mostly about practice". Three participants responded that experience was not a limiting factor all three were given design instruction $(\mathrm{Rx})$. The stand-out response from this group was that one participant wanted to follow the procedure given but would have done it differently themselves. The final response was given by the most experienced participant who said that their experience with the program was not limiting but their experience with gear modeling specifically was limiting. This is interesting to note because it underlines the fractal nature of expertise. The more experienced one becomes, the more they tend to realize they do not know. Perhaps more experienced participants can be more critical because their internal perspective allows for a better gauge of where their strengths and weaknesses lie. 
- What did you think about the spur gear modeling task? That is, did you find it interesting?

Twelve participants responded that the spur gear modeling task was interesting with several citing the difference, complexity, difficulty, or process as the reason for their interest. Three responded saying it was "average". One participant said it was interesting but confusing. It is noteworthy that all of the participants in the Open design category responded that the task was interesting where only five form the Prescribed category said the same (Table 8). This is in line with the thoughts described in this thesis such that with more autonomy, or in this case, less prescription, more positive relationships will be experienced with the task at hand. This interest is in spite of the fact that seven out of eight participants said that experience was a limiting factor,

- Did you feel like SolidWorks limited your ability to complete the design task? Would you have felt more focused if using another program?

Sixteen of the participants said that SolidWorks did not limit their ability. Several said their experience was the limiting factor not the program itself. Two responded that SolidWorks did limit their ability with the main reason being there were no instruction to help solve the problems experienced by a beginner. It is interesting to note that those two respondents were from the Prescribed category. Although given more instruction than the Open category, two participants felt like SolidWorks limited their ability compared to zero from the Open category. This could be coincidental but it is possible that since those from the Open category had to be completely self-reliant, they took more ownership for their 
failures where those with instructions felt frustration when the task could not be completed easily.

The most notable finding from the exit interviews were that most felt that their experience was the most limiting factor. This was reflected in Figure 10 with most of the participants ranking their relative competence with the task to be low. Although the perceived competence was low overall, most participants did not desire more instruction.

Of the seven who did want more instruction five were from the open design category and two were from the Rx deign category.

\section{General}

Several limitations uncovered during this study should be mentioned. Frist, when taking the CSUQ, it is unclear whether all participants were considering the same system. Some participants may have been considering the SolidWorks graphic user interface, others may have considered the work instructions alone, and others still may have considered the two in conjunction. The CSUQ survey results may be skewed in some ways as a result of these considerations. Also, several participants had reported trouble finding the testing site. This is important because a novel environment and unforeseen stressors such as trouble finding the room or time constraints could have affected the participants' flow experience. Although it should be known that every participant came to the same testing environment and faced the same time constraints.

With these limitations in mind, the implications of the findings discussed in this section are numerous. First the relationship between the relatively high correlation of task 
absorption (AA-Open) to information quality (InfoQ-Open) and the skill versus demand chart should be expanded upon. As previously discussed, the quality of information and the relative skill versus demand balance control the preconditions of the flow experience. An ability to give quality information to a person who has a skills demand challenge that are in balance will help elicit flow state. Now take that perspective and reverse the cause and effect. Reported flow will likely arise when the high-quality information and a perceived fit of skills and demand are given. What can possibly be the biggest takeaway from this thesis is that flow may be an indicator for a healthy and sustainable system. It is not that a system should be designed to elicit flow for its benefits as a psychological state but instead if the flow of the worker is monitored periodically it can be derived that they are receiving quality information and the demands of their work are in balance with their skill set.

Amidst the global pandemic, during which this thesis was written, it has never been clearer that the critical way to proceed as a species is with sustainability at the heart of our development. What quality information looks like in each system will be different and how to level the demands and skills of labor will need to be approached differently by different industries. Considering that, there is a difference between uniformity of action and uniformity of intention. As Industrial Engineers have standardized processes to a greater and greater degree, the quality of products has increased, and the cost has decreased. All operators acting uniformly within standard is often visualized to be the optimal path. The evidence speaks overwhelmingly to the contrary. Without decent work and the education of our labor force to act with uniform intention, the systems that have been built to fulfill human desires will not be sustainable. The action of the worker need not be 
standardized but their intention must be in line with that of their employers. The operator must have a seat at the table instead of being manipulated blindly as a numerical figure. When a worker experiences flow in the current system, it is despite the system that their personality allows them to find the song within the cacophony and to revel in the challenges at hand. A future where a worker experiences flow in synchronicity with the system may create the sustainable future which will provide future generations the ability to learn and grow as human beings and to create more sustainable systems. 


\section{FUTURE WORK}

There are several suggestions for future work based on the results and discussion of this thesis. The first and most accessible is to run at least one more iteration of the experiment described in this study with a larger sample size. Some potentially significant findings were highlighted in the discussion section which, can be confirmed (or disproven) with a larger sample size. Under the extenuating circumstances faced during this study it was not possible to complete the originally intended experiment. Completing that experiment as it was initially intended could bring a greater understanding of the effects of experience versus design prescription on the flow experience.

Based on the results of this study, more research should be done into what makes information higher quality. A greater understanding of this could allow engineers to design systems with the right quality of information, not necessarily meaning more information, to allow for the preconditions for the flow experience to arise. Some literature already exists in this field of research such as the MIT developed AIMQ methodology (Lee, Strong, Kahn, \& Wang, 2002). Research can also be done into how a person's perceived importance or perceived outcome importance of their actions relate to the quality level of a product whether that be a service or otherwise.

It would be interesting to take several existing work environments with varying levels of workforce morale and quality and plot the workforce's location on the Csikszentmihalyi's original flow model. This simple tool could inform process engineers as to where to operator feels the demand of the system is versus their skills especially after

any process changes are made. Note that it is an implication of this thesis that flow is a 
consequence of a well- managed system and striving for flow will prove a fruitless effort if it means neglecting the needs of the system.

Maybe the most important of all, studies should be done into how workforce education can lead to unified intention of a system. While that is an abstract statement, Horace Mann famously quoted, "Education then, beyond all other devices of human origin, is the great equalizer of the conditions of men, the balance-wheel of the social machinery" (Mann, 1868). From the perspective of a Human Factors Engineer, that speaks volumes as to what the primary objective in designing a system should be. Instead of keeping the workforce dependent on procedure to create unified action, the system's primary objective should be to educate the worker such that their actions can add value to the system organically. 


\section{CONCLUSION}

This thesis first introduced the concepts of Flow Theory (Csikszentmihalyi 1990, Engeser 2012) and Cognitive Evaluation Theory (Deci and Ryan 1985). Based on the literature surrounding these constructs, an experiment was constructed to isolate the effects of design autonomy on the flow experience. During this process the world changed at lightning speed in response to the global spread of the novel coronavirus causing the COVID-19 disease. After making the necessary amendments, data collection was completed and analyzed under an adjusted experimental design. The results of the analysis found no statistically significant difference between the flow experienced with open design (no standard operating procedure) or the flow experienced with prescribed design (with standard operating procedure). Neither of the two hypotheses presented in this thesis were empirically supported.

Subjects presented with an open design were not more likely to report flow than subjects presented with prescriptive design. Further, users who report high usability while interacting with a product were not more likely to report experiencing flow, though it would undoubtedly be worth further defining the correlational relationships between the phenomenon reported by the subscales of the FSS and CSUQ. Although this thesis lives mostly in the realm of theory, the potential implications of the study and integration of these concepts into modern systems should be further explored.

A future exists in which the consistency and frequency of workforce flow is the marker of a healthy and sustainable system. The road to this future will undoubtedly be full of challenges but I would like to reference a participant in this study. A young student, 
still a teenager, was given a task with little instruction or experience. Instead of withering away and blaming these things for their shortcomings, they reveled in the challenge and moved forward with curiosity and creativity abreast. So, we must proceed, not to reach out destination, but to revel in the beauty of the journey in search of knowledge to better understand where our next steps must be. Only then will flow arise. 


\section{REFERENCES CITED}

Abuhamdeh, S. (2012). A Conceptual Framework for the Integration of Flow Theory and Cognitive Evaluation Theory. In S. Engeser, Advances in Flow Research (pp. 109-121). New York: Springer Science+Business Media, LLC.

Aragwal, R., \& Karahanna, E. (2000). Time flies when you're having fun: Cognitive absorption and beliefs about information technology usage. MIS Quarterly, 24(4), 665-694.

Bekker, M., \& Assen, M. (2006). A Short Form of the Autonomy Scale: Properties of the Autonomy-Connectedness Scale (ACS-30). Journal of Personality Assessment, $86,51-60$.

Blanck, P. D., Reis, H. T., \& Jackson, L. (1984). The effects of verbal reinforcements on intrinsic motivation for sex-linked tasks. Sex Roles, 10, 369-387.

Creating Spur and Helical Gears in SolidWorks. (n.d.). Retrieved from Learn SolidWorks: https://learnsolidworks.com/solidworks_tutorials/creating-spurhelical-gears-solidworks

Csikszentmihalyi, M. (1973). The personality of a young artist: An empirical and theoretical exploration. British Journal of Psychology, 64, 91-104.

Csikszentmihalyi, M. (1975). Beyond boredom and anxiety: Experiencing flow in work and play. San Francisco: Jossey-Boss.

Csikszentmihalyi, M. (1990). flow The Psychology of the Optimal Experience. In The Autotelic Experience (p. 67). New York: HarperCollins.

Csikszentmihalyi, M., \& Larson, R. (1987). Validity and reliability of the Experience Sampling Method. Journal of Nervous and Mental Disease, 175, 281-294. 
Csikszentmihalyi, M., \& LeFevre, J. (1989). Optimal experience in work and leisure . Journal of Personality and Social Psychology, 56, 815-822.

Csikszetmihalyi, M., \& Bennet, S. (1971). An exploratory model of play. American Anthropologist, 45-58.

Davis, F. D. (1989). Perceived usefulness, perceived ease of use, and user acceptance of information technology. MIS Quarterly, 13, 319-340.

Deci, E. L. (1971). Effects of externally mediated rewards on intrinsic motivation. Journal of Personality and Social Psychology, 18, 105-115.

Deci, E. L., \& Ryan, R. M. (1980). The empirical exploration of intrinsic motivational process. In L. Berkowitz, Advances in experimental social psychology (pp. 3980). New York: Academic.

Deci, E. L., \& Ryan, R. M. (1985). Intrinsic motivation and self-determination in human behvior. New York: Plenum.

Deci, E. L., \& Ryan, R. M. (2000). The "what" and "why" of goal pursuits: Human needs and the self-determination behavior. Psychology Inquiry, 11, 227-268.

Deitrich, A. (2003). Functional neuroanatomy of altered states of consciouness. The transient hypofrontality hypothesis. Consciouness and Cognition, 12, 231-256.

Dietrich, A. (2004). Neurocognitive mechanisms underlying the experience of flow. Consciousness and Cognition, 13, 746-761.

Engeser , S., \& Schiepe-Tiska, A. (2012). Historical Lines and an Overview of Current Research on Flow. In S. Engeser, Advances in Flow Research (pp. 1-22). New York: Springer Science+Business Media, LLC.

Engeser, S. (2012). Advances in Flow Research . New York: Springer. 
Getzel, J. W., \& Csikszentmihalyi, M. (1966). The study of creativity in future artists: the criterion problem. In O. J. Harvey, Experience, structure, and adaptability. New York: Springer.

Immordino-Yang, M. H., Christodoulou, J. A., \& Singh, V. (2012). Rest Is Not Idleness: Implications of the Brain's Default Mode for Human Development and Education. Perspectives on Psychological Science, 7, 352.

Keller , J., Ringelhan, S., \& Blomann, F. (2011). Does skills-demands-compatability result in instrinsic motivation? Experimental test of a basic notion proposed in the theory of flow-experiences. Journal of Positive Psychology, 6, 408-417.

Keller, J., \& Landhäußer , A. (2012). The Flow Model Revisited. In S. Engeser, Advances in Flow Research (pp. 51-64). New York: Springer Science+Business Media,LLC.

Landhäußer, A., \& Keller, J. (2012). Flow and Its Affective, Cognitive, and PerformanceRelated Consequences. In S. Engeser, Advances in Flow Research (pp. 65-85). New York: Springer Science+Business Media, LLC.

Landhäußer, A., Keller, J., \& Frommherz, A. (2011). The paradox of work reconsidered: A systematic test based on the Day Reconstruction Method. Manuscript in preperation.

Lee, Y. W., Strong, D. M., Kahn, B. K., \& Wang, R. Y. (2002). AIMQ: a methodology for information quality assessment. Information \& Management, 40, 133-146.

Lewis, J. R. (1995). IBM Computer Usability Satisfaction Questionnaires: Psychometric Evaluation and Instruction for Use. International Journal of Human-Computer Interaction, 7(1), 57-78. 
Lowry, B. P., Gaskin, J., Twyman, N., Hammer, B., \& Roberts, T. (2012). Taking 'Fun and Games' Seriously: Proposing the Hedonic-Motivation System Adoption Model (HMSAM). Journal of the Assocation for Information Systems, vol 14(11), 617-671.

Mann, H. (1868). twelfth annual report to the Massachusetts State Board of Education. In M. M. Mann, Life and Works of Horace Mann, vol. 3 (p. 669).

Moneta, G. B. (2004). The flow experience across cultures. Journal of Happiness Studies, $5,115-121$

Moneta, G. B. (2012). On the Measurement and Conceptualization of Flow. In S. Engeser, Advances in Flow Research (pp. 23-50). New York: Springer Science+Business Media.

Morae. (n.d.). Retrieved from TechSmith: https://www.techsmith.com/morae.html Morae Components and Features. (n.d.). Retrieved from TechSmith: https://www.techsmith.com/morae-features.html

Pfiefer, C. (2012). Psychophsyiological Correlates of Flow-Experience. In S. Engeser, Advances in Flow Research (pp. 139-164). New York: Springer Science+Business Media, LLC.

Raichle, M. E. (2015). The Brain's Default Mode Network. Annual Review of Neuroscience, 38, 433-447.

Raichle, M. E., MacLeod, A. M., Snyder, A. Z., Powers, W. J., Gusnard, D. A., \& Shulman, G. L. (2001). A default mode of brain function. Proceeding of the National Academy of Sciences, 98 (2), (pp. 676-682). 
Reeve, J., \& Deci, E. L. (1996). Elements of the competitive situation that affect intrinsic motivation. Personality and Social Psychology Bulletin, 22, 24-33.

Reinberg, F., Vollmeyer, R., \& Engeser, S. (2003). Die Erfassung des Flow-Erlebens [The assessment of flow experience]. In J. Stiensmeier-Pelster, \& F. Rheinberg, Diagnostik van Motivation und Selbstkonzept (pp. 261-279). Göttingen: Hogrefe.

Ryan, R. M., \& Deci, E. L. (2000). Intrinsic and Extrinsic Motivations: Classic Definitions and New Directions . Contemporary Educational Psychology 25, 5467.

Schüler, J. (2007). Arousal of flow experience in learning setting ad its effects on exam performance and affect. Zeitschrift für Pädagogische Psychologie, 21, 217-227.

SolidWorks. (n.d.). Retrieved from Dassault Systemes: https://www.3ds.com/productsservices/solidworks/

SolidWorks Products \& Solutions. (n.d.). Retrieved from SolidWorks: https://www.solidworks.com/products-and-solutions

Van der Heijden, H. (2004). User acceptance of hedonic information systems. MIS Quarterly, 28(4), 695-704.

Venkatesh, V. (2000). Determinants of percieved ease of use: Integrating control, intrinsic motivation, and emotion into the technology acceptance model. Infomation Systems Research, 11(4), 342-365. 


\section{APPENDIX I FLOW SHORT SCALE}

1. I feel just the right amount of challenge

2. My thoughts/activities run fluidly and smoothly

3. I do not notice time passing

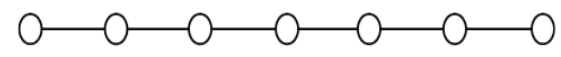

4. I have no difficulty concentrating<smiles>OOOOOOOO</smiles>

5. My mind is completely clear<smiles>OOOOOOOOO</smiles>

6. I am totally absorbed in what I am doing

7. The right thoughts/movements occur of their own accord

8. I know what I have to do each step of the way

9. I feel that I have everything under control<smiles>OOOOOOOO</smiles>

10. I am completely lost in thought<smiles>OOOOOOOO</smiles>

11. Something important to me is at stake here

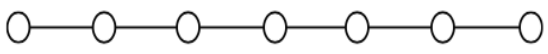

12. I must not make any mistakes here

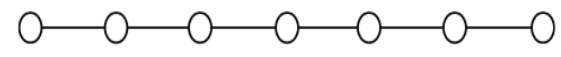

13. I am worried about failing<smiles>OOOOOOOO</smiles><smiles>OOOOOOOO</smiles><smiles>OOOOOOOO</smiles><smiles>OOOOOOOO</smiles>
$\mathrm{O}-\mathrm{O}-\mathrm{O}-\mathrm{O}-\mathrm{O}-\mathrm{O}-\mathrm{O}$

- Compared to all other activities which I partake in, this one is ...

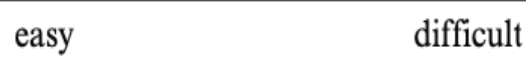

$\mathrm{O}-\mathrm{O}-\mathrm{O}-\mathrm{O}-\mathrm{O}-\mathrm{O}-\mathrm{O}-\mathrm{O}-\mathrm{O}$

- I think that my competence in this area is ...

- For me personally, the current demands are ...

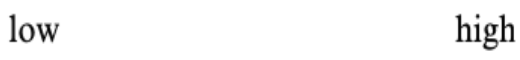

too tow too




\section{APPENDIX II CSUQ SURVEY}

\section{CSUQ: Computer System Usability Questionnaire}

Please rate the usability of the system.

\begin{tabular}{|c|c|c|c|c|c|c|c|c|}
\hline \multirow{2}{*}{1.} & \multirow[b]{2}{*}{ Overall, I am satisfied with how easy it is to use this system. } & \multicolumn{4}{|c|}{ strongly disagree } & \multicolumn{3}{|c|}{ strongly agree } \\
\hline & & 1 & 2 & 3 & 4 & 5 & 6 & 7 \\
\hline 2. & It was simple to use this system. & 1 & 2 & 3 & 4 & 5 & 6 & 7 \\
\hline 3. & I can effectively complete my work using this system. & 1 & 2 & 3 & 4 & 5 & 6 & 7 \\
\hline 4. & I am able to complete my work quickly using this system. & 1 & 2 & 3 & 4 & 5 & 6 & 7 \\
\hline 5. & I am able to efficiently complete my work using this system. & 1 & 2 & 3 & 4 & 5 & 6 & 7 \\
\hline 6. & I feel comfortable using this system. & 1 & 2 & 3 & 4 & 5 & 6 & 7 \\
\hline 7. & It was easy to learn to use this system. & 1 & 2 & 3 & 4 & 5 & 6 & 7 \\
\hline 8. & I believe I became productive quickly using this system. & 1 & 2 & 3 & 4 & 5 & 6 & 7 \\
\hline 9. & The system gives error messages that clearly tell me how to fix problems. & 1 & 2 & 3 & 4 & 5 & 6 & 7 \\
\hline 10. & Whenever I make a mistake using the system, I recover easily and quickly. & 1 & 2 & 3 & 4 & 5 & 6 & 7 \\
\hline 11. & $\begin{array}{l}\text { The information (such as online help, on-screen messages, and other documentation) } \\
\text { provided with this system is clear. }\end{array}$ & 1 & 2 & 3 & 4 & 5 & 6 & 7 \\
\hline 12. & It is easy to find the information I needed. & 1 & 2 & 3 & 4 & 5 & 6 & 7 \\
\hline 13. & The information provided for the system is easy to understand. & 1 & 2 & 3 & 4 & 5 & 6 & 7 \\
\hline 14. & The information is effective in helping me complete the tasks and scenarios. & 1 & 2 & 3 & 4 & 5 & 6 & 7 \\
\hline 15. & The organization of the information on the systems screens is clear. & 1 & 2 & 3 & 4 & 5 & 6 & 7 \\
\hline 16. & The interface of the system is pleasant. & 1 & 2 & 3 & 4 & 5 & 6 & 7 \\
\hline 17. & I like using the interface of this system. & 1 & 2 & 3 & 4 & 5 & 6 & 7 \\
\hline 18. & This system has all the functions and capabilities I expect it to have. & 1 & 2 & 3 & 4 & 5 & 6 & 7 \\
\hline 19. & Overall, I am satisfied with this system. & 1 & 2 & 3 & 4 & 5 & 6 & 7 \\
\hline
\end{tabular}




\section{APPENDIX III OPEN DESIGN SOP}

\section{Overview:}

You are tasked with modeling a spur gear with 25 teeth. On this page are variables and equations which are optional to use. Please use the first image below as a reference for the given equations. Please use the second image is an example of a spur gear.

\section{Variables:}

Number of Teeth $=25$

Module $=2$

\section{Equations:}

Pitch Diameter $=$ Module $*$ Number of Teeth

Outside Diameter $=($ Number of Teeth +2$) *$ Module

Root Diameter [measured from outer to inner ring] $=$ Module $*$ if $($ Module $=>1.25,2.25,2.4)$

Tooth-to-Tooth Distance $=180 /$ Number of Teeth

Fillet $=.3 *$ Module
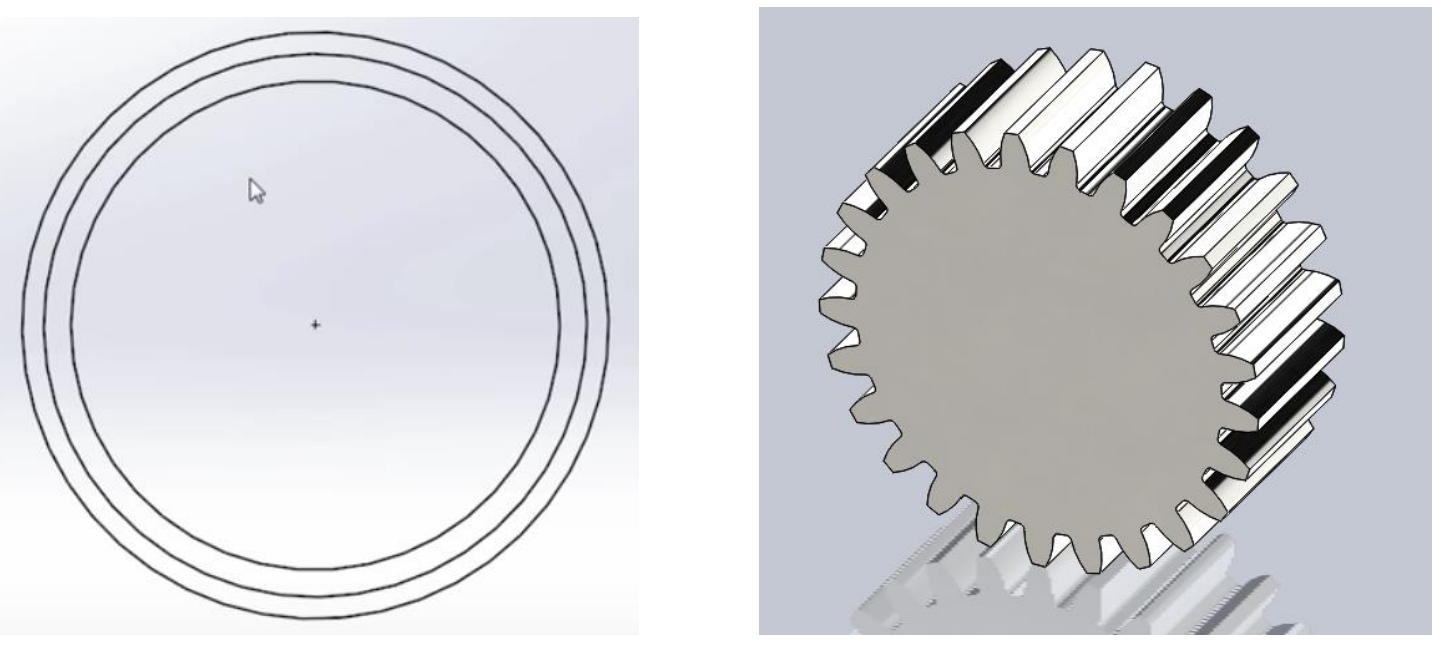

Outer ring $=$ Outside ; middle ring $=$ pitch; inner ring $=$ root

Example Spur Gear 


\section{APPENDIX IV PRESCRIBED DESIGN SOP}

\section{Overview:}

This standard operating procedure is to be used to model a spur gear in SolidWorks using the metric module system. It will take you through the steps from a blank SolidWorks display to the finalized gear in SolidWorks. All information and equations necessary to complete the modeling task will be provided to you in this document.

\section{Variables:}

Number of Teeth $=25$

Module $=2$

\section{Equations:}

Pitch Diameter $=$ Module $*$ Number of Teeth

Outside Diameter $=($ Number of Teeth +2$) *$ Module

Root Diameter [measured from outer to inner ring] $=$ Module $*$ if $($ Module $=>1.25,2.25,2.4)$

Tooth-to-Tooth Distance $=180 /$ Number of Teeth

Fillet $=.3 *$ Module
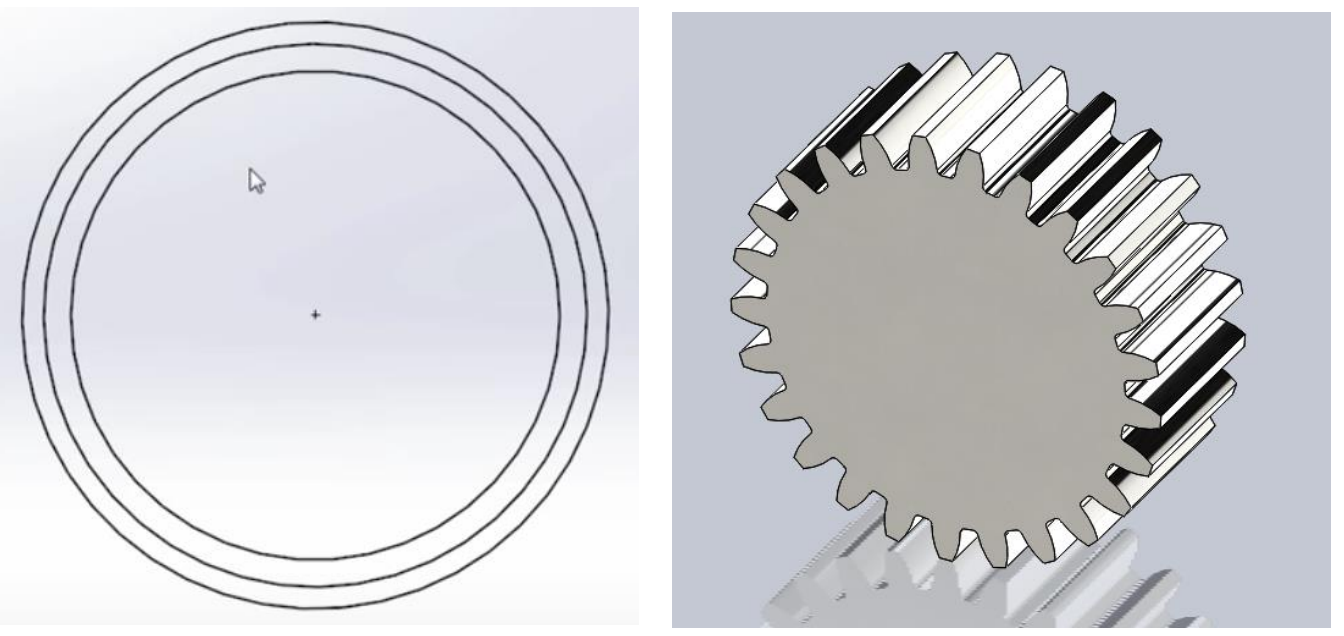

Outer ring $=$ Outside , middle ring $=$ pitch ; inner ring $=$ root

\section{Procedure:}

Ensure units are metric**

1. Assign Global Variables 
a. Using Equation Manager, assign given values for Number of Teeth and Module

2. Create Gear Body

a. Sketch circle on front plane

i. Dimension using Pitch Diameter equation

b. Sketch second circle on front plane

i. Dimension using Outside Diameter equation

c. Sketch third circle on front plane

i. Dimension from outside circle to root circle

ii. Use Root Diameter equation (measured from circle in part b. to newly sketched circle)

d. Exit Sketch

3. Extrude Sketch 1

a. Select Extrude Command

i. Select outside diameter of sketch 1

ii. Set mid-plane

iii. Set $\mathrm{D} 1=20 \mathrm{~mm}$

4. Create Tooth Profile

a. Sketch a centerline on front plane

i. Line goes from origin to outside diameter

b. Sketch a 3-point arc

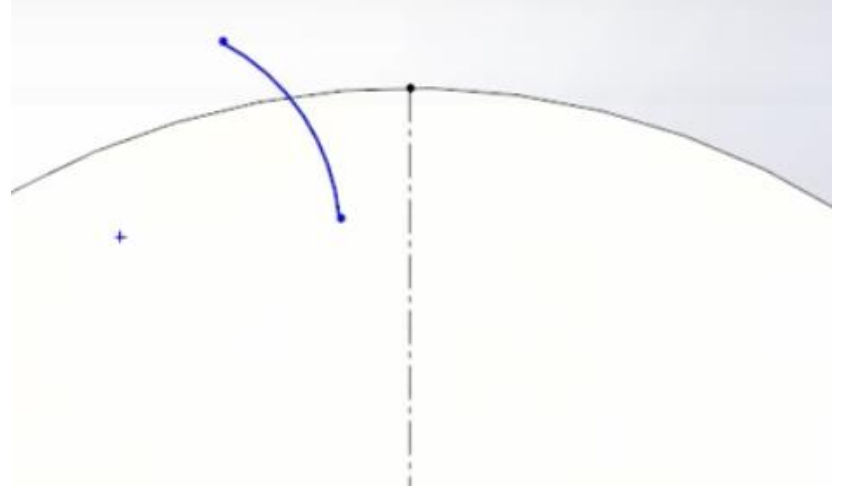

c. Using Mirror Entities tool, mirror arc about centerline

d. Turn on sketch visibility for Sketch 1

i. Located in part tree

e. Using the convert entities tool, select the root diameter 
i. Snap end of arc to root diameter

ii. Using trim entities tool, trim the root diameter

f. Using offset entities tool, offset outside diameter by $1 \mathrm{~mm}$

i. Snap top of arc to offset line

ii. Trim offset line

5. Define Sketch 2

a. Create a horizontal construction line

b. Select the geometries shown here

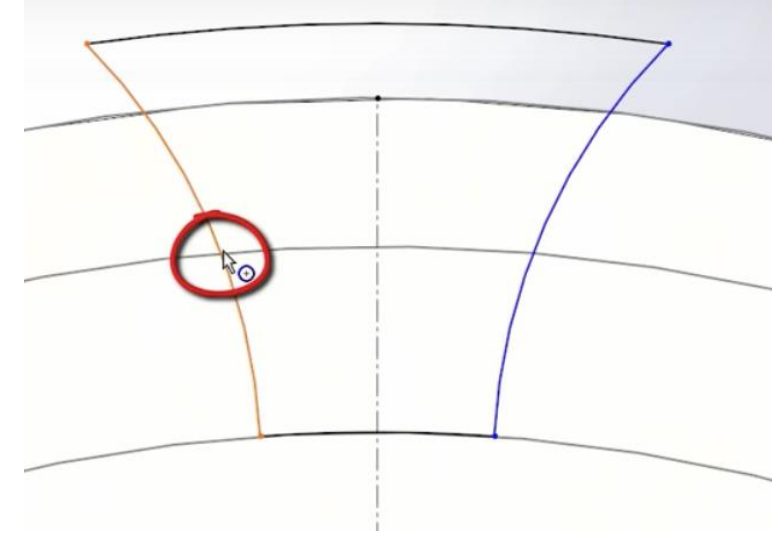

i. Create point intersect relationship

ii. Repeat process on other side

c. Create construction line from origin to bottom point of arc

i. Create tangent relationship

d. Create a construction line from the centerline to the outside diameter

i. Create Tangent relationship to arc

ii. Create coincident relationship with construction line from $b$.

iii. Dimension angle to 20 degrees

e. Create centerline for next tooth

i. From origin to outside of tooth profile 


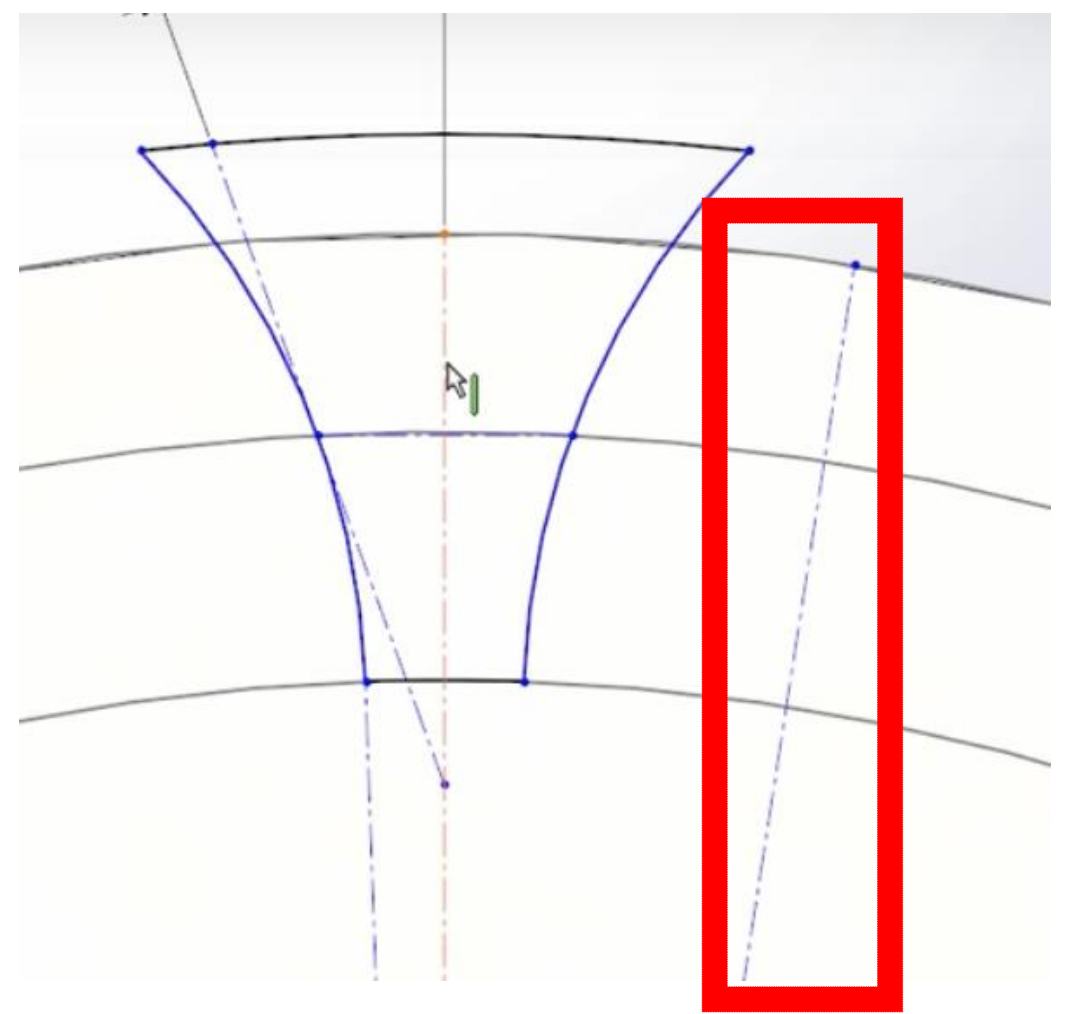

ii. Dimension centerline to centerline using Tooth-to-Tooth Distance equation

f. Create construction line as shown

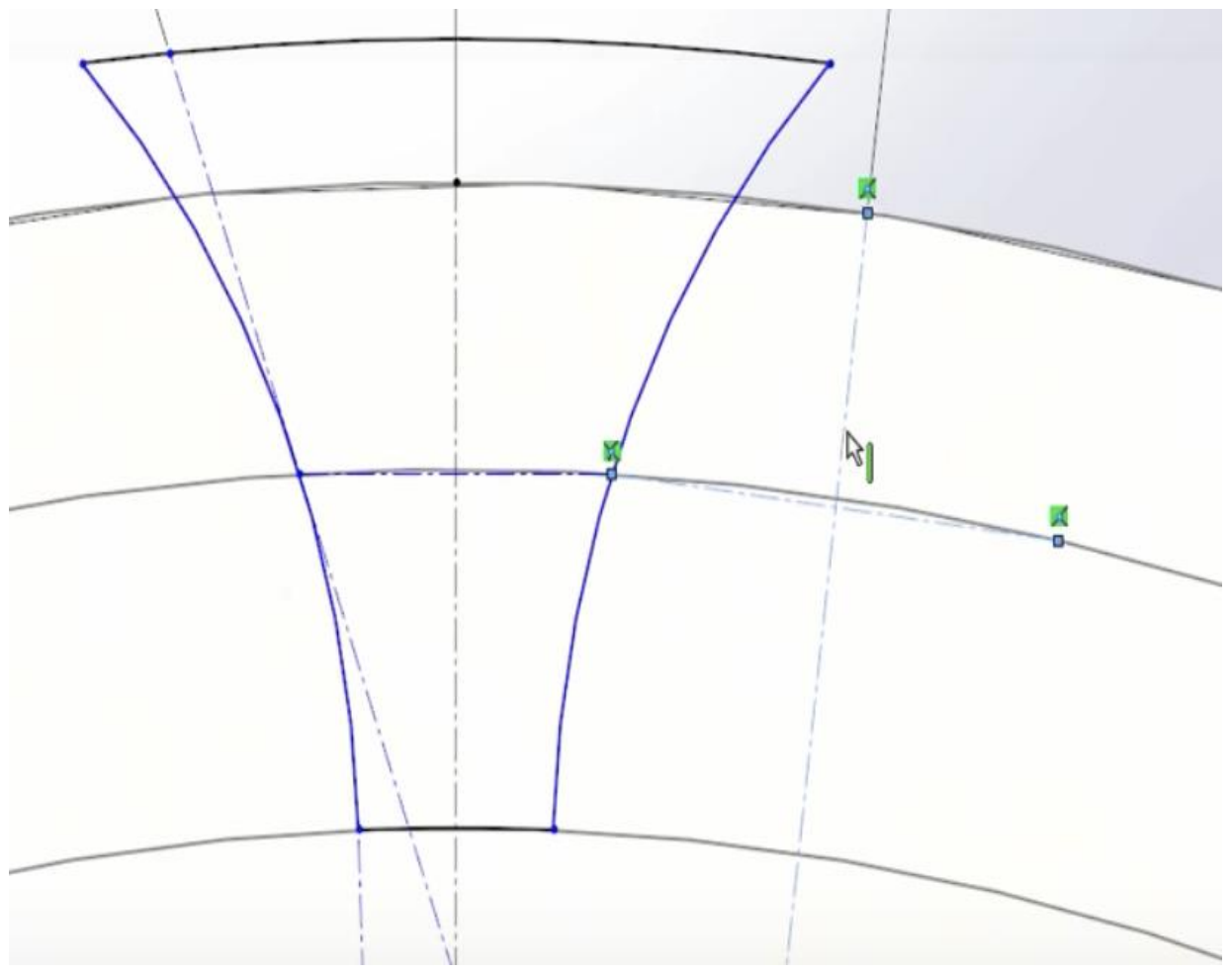

i. Create equal relationship to horizontal construction line in part a. 
6. Extrude Cut Sketch 2

a. Though all both directions

7. Fillet Tooth

a. Select both bottom edges of tooth profile

b. Use Fillet equation to dimension

8. Pattern Teeth

a. Use circular pattern tool

i. Select cut and fillet

ii. Select outside face

iii. Specify $=$ Number of Teeth 


\section{APPENDIX V OVER-PRESCRIBED DESIGN}

\section{Overview:}

This standard operating procedure is to be used to model a spur gear in SolidWorks using the metric module system. It will take you through the steps from a blank SolidWorks display to the finalized gear in SolidWorks. All information and equations necessary to complete the modeling task will be provided to you in this document.

\section{Variables:}

Number of Teeth $=25$

Module $=2$

\section{Equations:}

Pitch Diameter $=$ Module $*$ Number of Teeth

Outside Diameter $=($ Number of Teeth +2$) *$ Module

Root Diameter $=$ Module $*$ if $($ Module $=>1.25,2.25,2.4)$

Tooth-to-Tooth Distance $=180 /$ Number of Teeth

Fillet $=.3 *$ Module

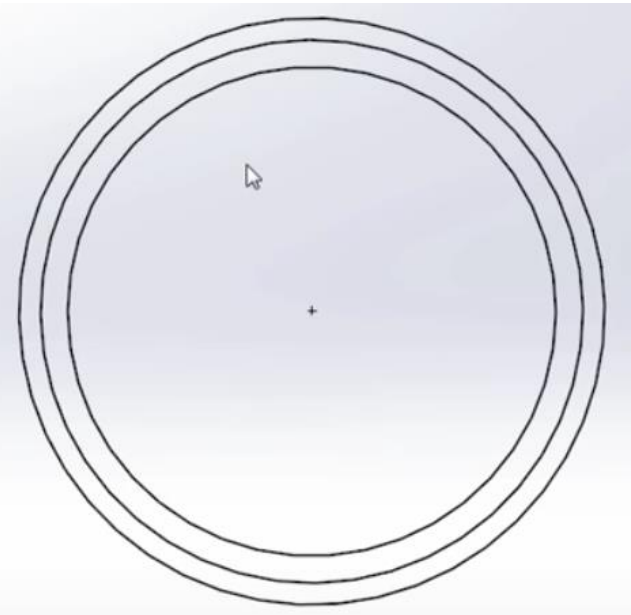

Outer ring $=$ Outside , middle ring $=$ pitch; inner ring $=$ root

\section{Procedure:}

Ensure units are metric**

1. Assign Global Variables

a. Right mouse-click on component icon 
b. Go to hidden tree items

c. Choose equations

d. Select Manage Equations

e. Select Global variable section

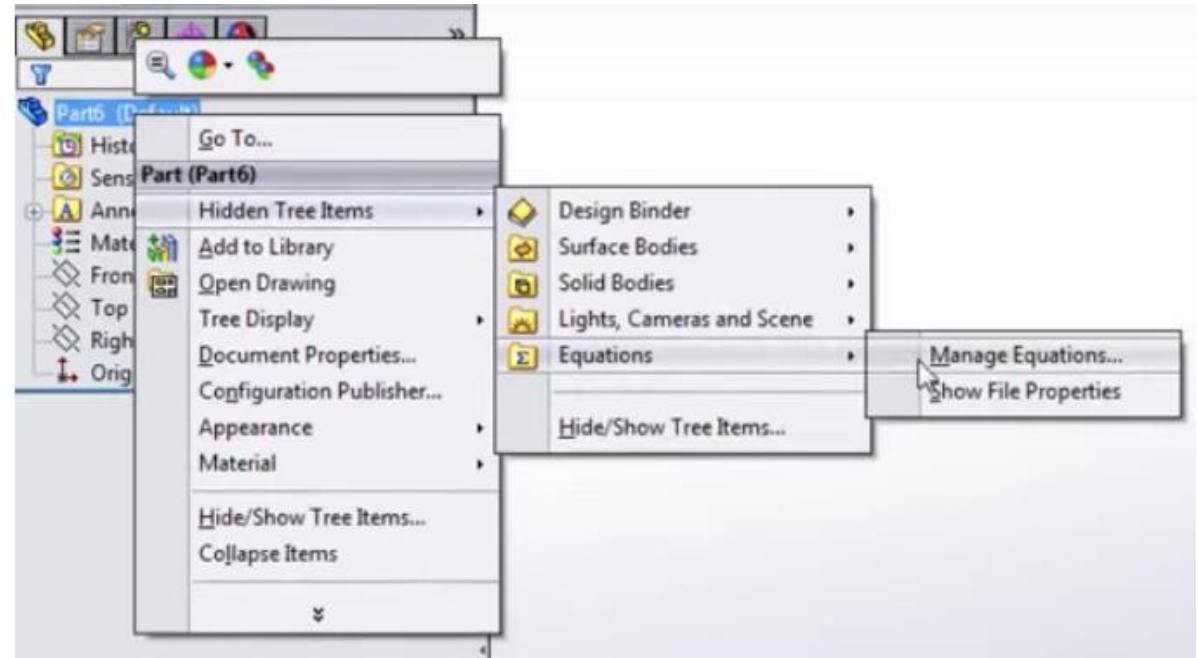

f. Name first variable "Module"

g. Press tab key, enter value " $2 \mathrm{~mm}$ "

h. Select add global variable

i. Name second variable "Number of Teeth"

j. Press tab, enter value " 25 "

(See image below for complete table)

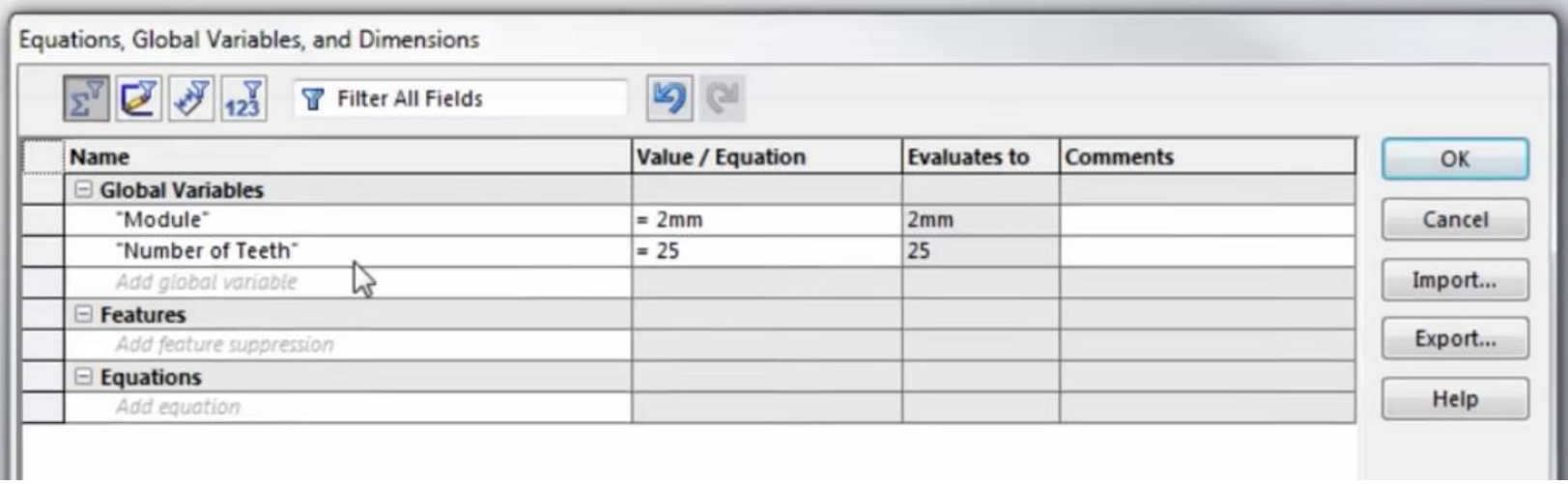

2. Create Gear Body

a. Sketch circle on front plane

i. Select front plane from the component tree

ii. Activate sketch tab by left clicking "sketch" in toolbar 
iii. Select circle from sketch tab

iv. Left click on origin

v. Drag cursor out and left click

vi. Select smart dimension from sketch tab

vii. Left click on outside of circle

viii. In smart dimension enter the equal sign "="

ix. Left click Global Variables

1. Select Module

X. Now enter an asterisk with spaces around it " *"

xi. Repeat step ix.

1. Select Number of Teeth

xii. Click Enter

1. You should see a red Sigma and the number 50

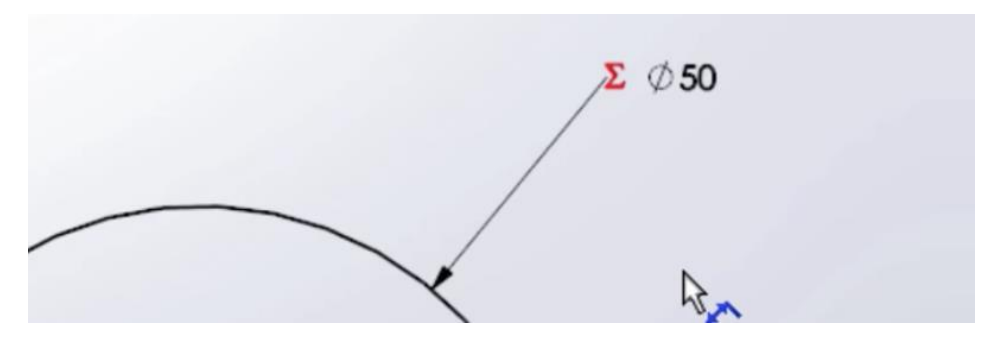

b. Sketch second circle on front plane

i. Repeat steps iii - viii from a.

1. Select Number of Teeth (25) from drop down

ii. Next, enter "+2) * Mod"

1. Select Module $(2 \mathrm{~mm})$ from drop down

iii. Press enter twice and click anywhere outside of the sketch

1. You should now see a red Sigma and the number 54

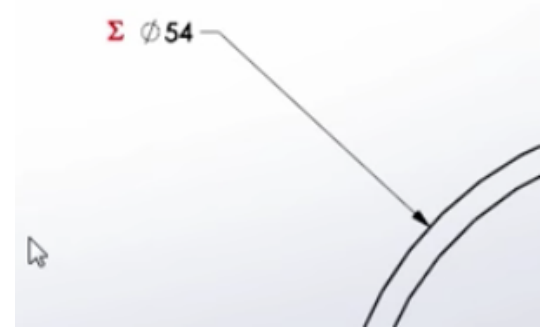

c. Sketch third circle on front plane 
i. Repeat steps iii-vi from a.

1. Ensure the circle is smaller than the previous two circles

ii. Left click the outermost circle then left click the innermost circle iii. In smart dimension, enter "=Mod"

1. Select Module (2mm) from the drop down iv. Now enter "* if(Mod"

1. Select module $(2 \mathrm{~mm})$ from the drop down

v. Next, enter " $=>1.25,2.25,2.4) "$

vi. Press enter twice.

vii. Your final sketch should look like this:

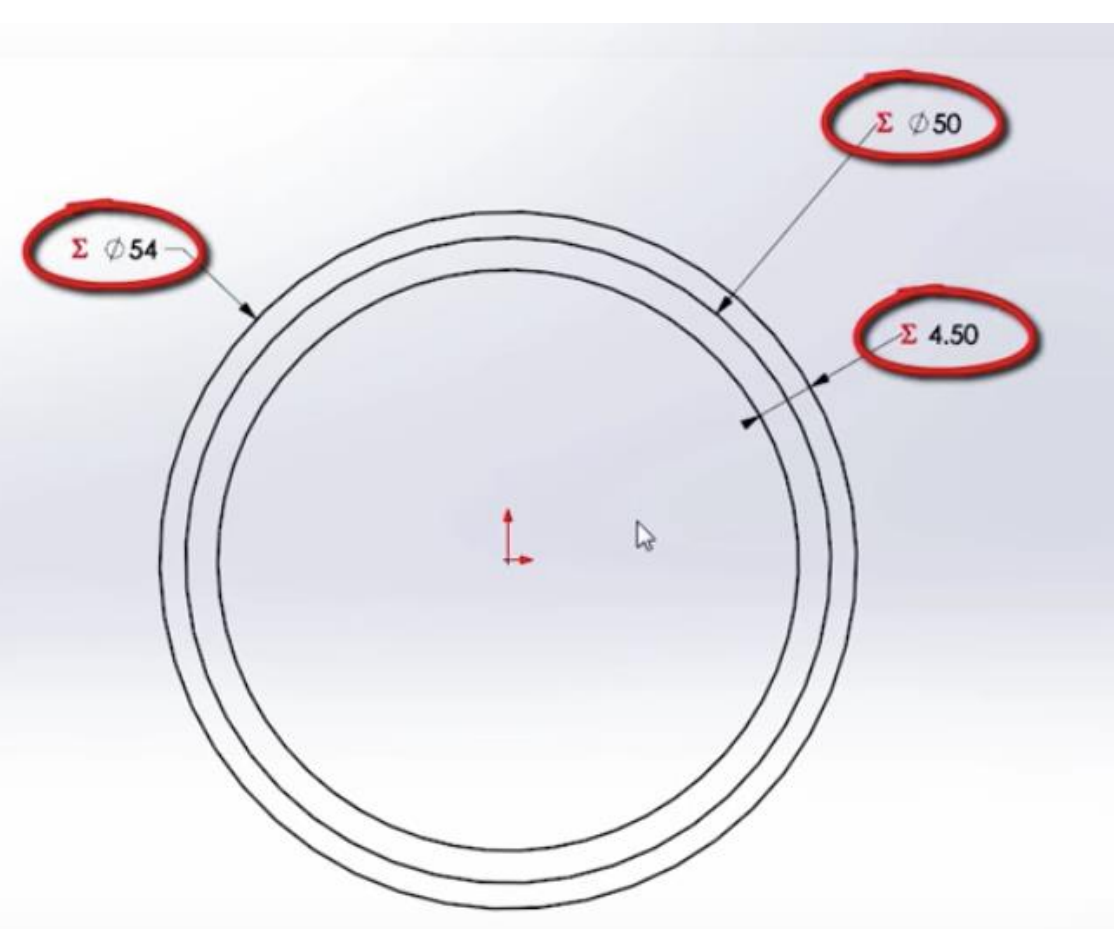

d. Exit Sketch by clicking the blue symbol at the top right of the interface

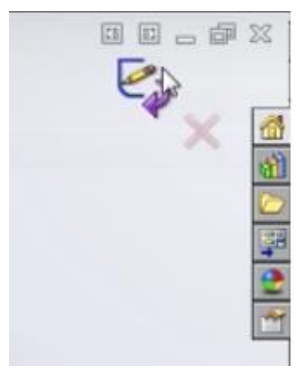

3. Extrude Sketch 1

a. Left click Sketch 1 from part tree to select 

b. Left click Features tab from tool bar
c. Left click Extruded Boss/Base from Features tab
d. Left click outside diameter
e. Right click and select Mid Plane
f. Left click and hold on gray arrow in center of sketch and drag to $20 \mathrm{~mm}$
g. Right click and select the green check mark OK
h. Your final extruded part should look like this

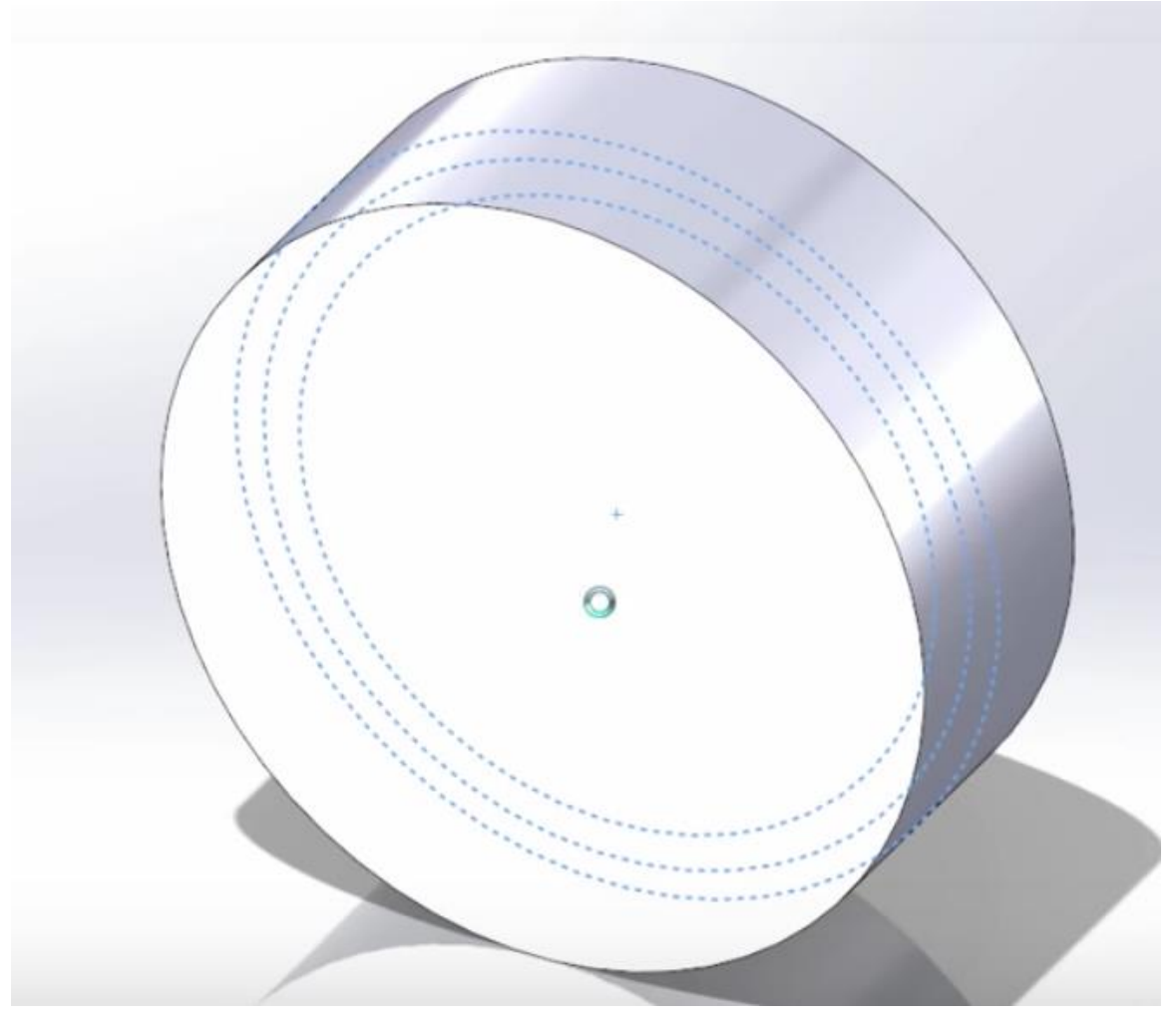

4. Create Tooth Profile
a. Select front plane from part tree
b. Press Ctrl +1 to see the front view
c. Activate sketch tab from tool bar
d. Click drop down arrow next to line

i. Select centerline

e. Left click on origin then left click on outer diameter directly above (perpendicular)

f. Right click and select "select"

g. Sketch a 3-point arc to the left of the centerline 
i. In sketch tab, click drop down arrow next to CenterPoint arc

ii. Select 3point arc

iii. Left click just outside of circle and left click twice inside circle (ensure arc looks like the image below) ** Ctrl $+\mathrm{Z}$ will undo last step if a mistake was made

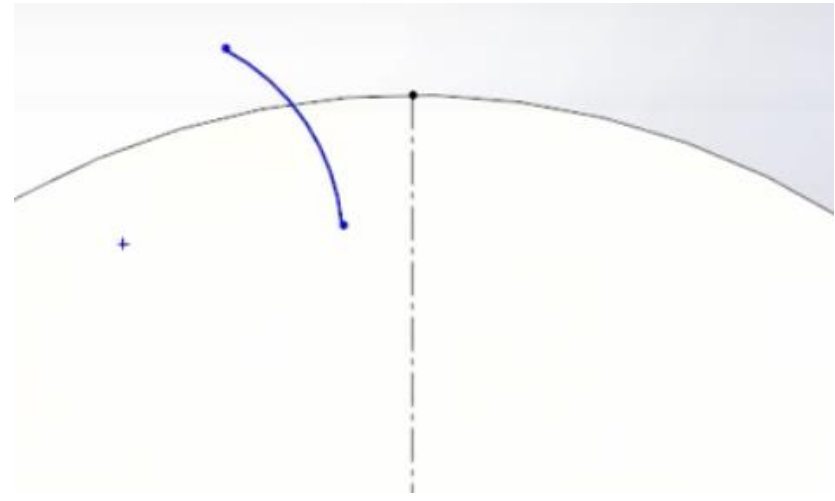

h. Select Mirror Entities from Sketch tab

i. Select newly sketched 3 point arc

ii. Right click, then select centerline

iii. Right click, select green check mark OK

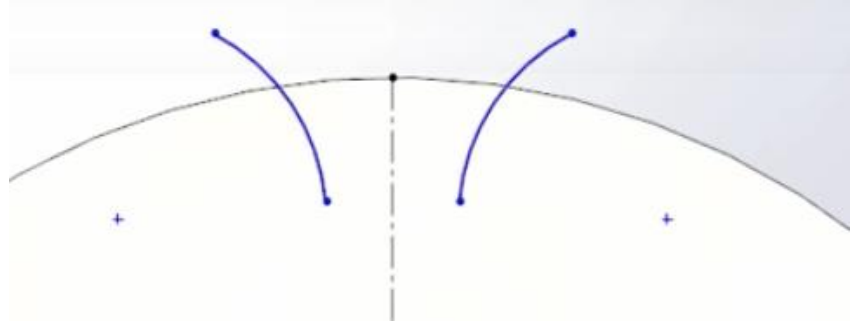

i. Turn on sketch visibility for Sketch 1 by selecting the drop-down arrow from Boss-Extrude 1 in the part tree, then right clicking Sketch 1 and left clicking the eyeball "Show"

j. Next, select convert entities from the sketch tab and left click the innermost circle, then right click to select ok

k. Now, snap the bottom edge of the arc to the innermost circle 


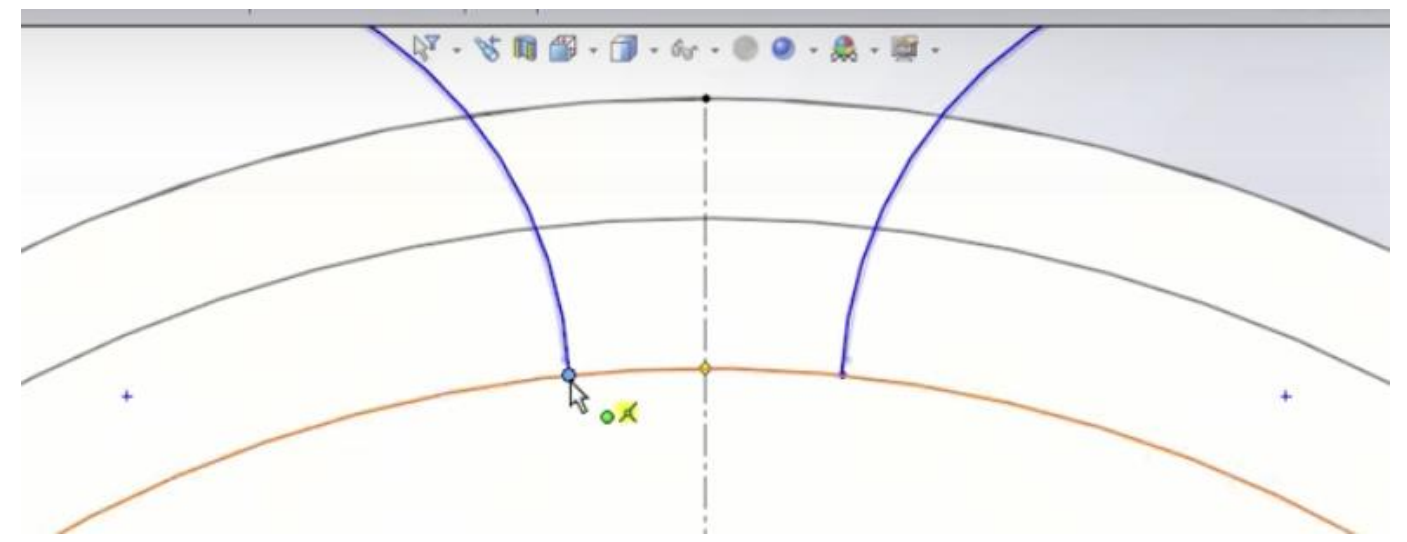

1. Select the trim entities tool from the Sketch tab and select Trim to closest form the menu on the left-hand side of the interface.

i. Click the innermost circle outside of the two arcs

ii. Click the green checkmark to complete trim

$\mathrm{m}$. Using offset entities tool from the Sketch tab, left click the outermost circle.

i. Set distance to $1 \mathrm{~mm}$ and press enter then right click and click ok

ii. Snap the top of the arc to the newly offset line

iii. Repeat step I but this time with the offset circle

5. Define Sketch 2

a. Create a horizontal construction line

b. Select the geometries shown here

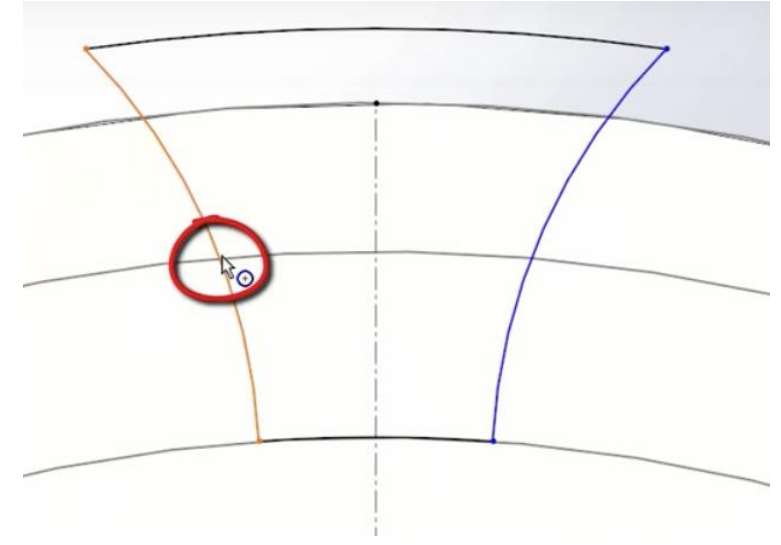

i. Create point intersect relationship

ii. Repeat process on other side

c. Create construction line from origin to bottom point of arc

i. Create tangent relationship

d. Create a construction line from the centerline to the outside diameter 
i. Create Tangent relationship to arc

ii. Create coincident relationship with construction line from b.

iii. Dimension angle to 20 degrees

e. Create centerline for next tooth

i. From origin to outside of tooth profile

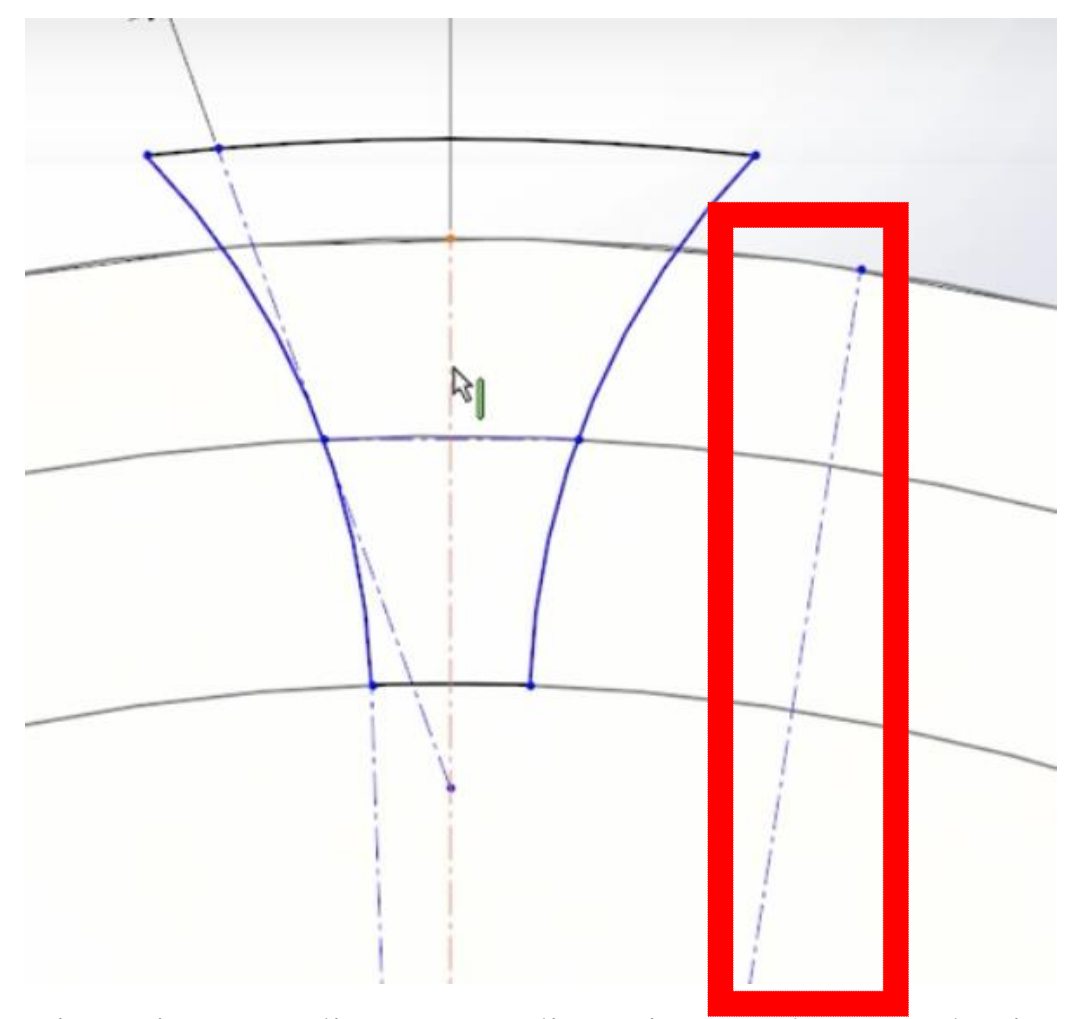

ii. Dimension centerline to centerline using Tooth-to-Tooth Distance equation

f. Create construction line as shown 


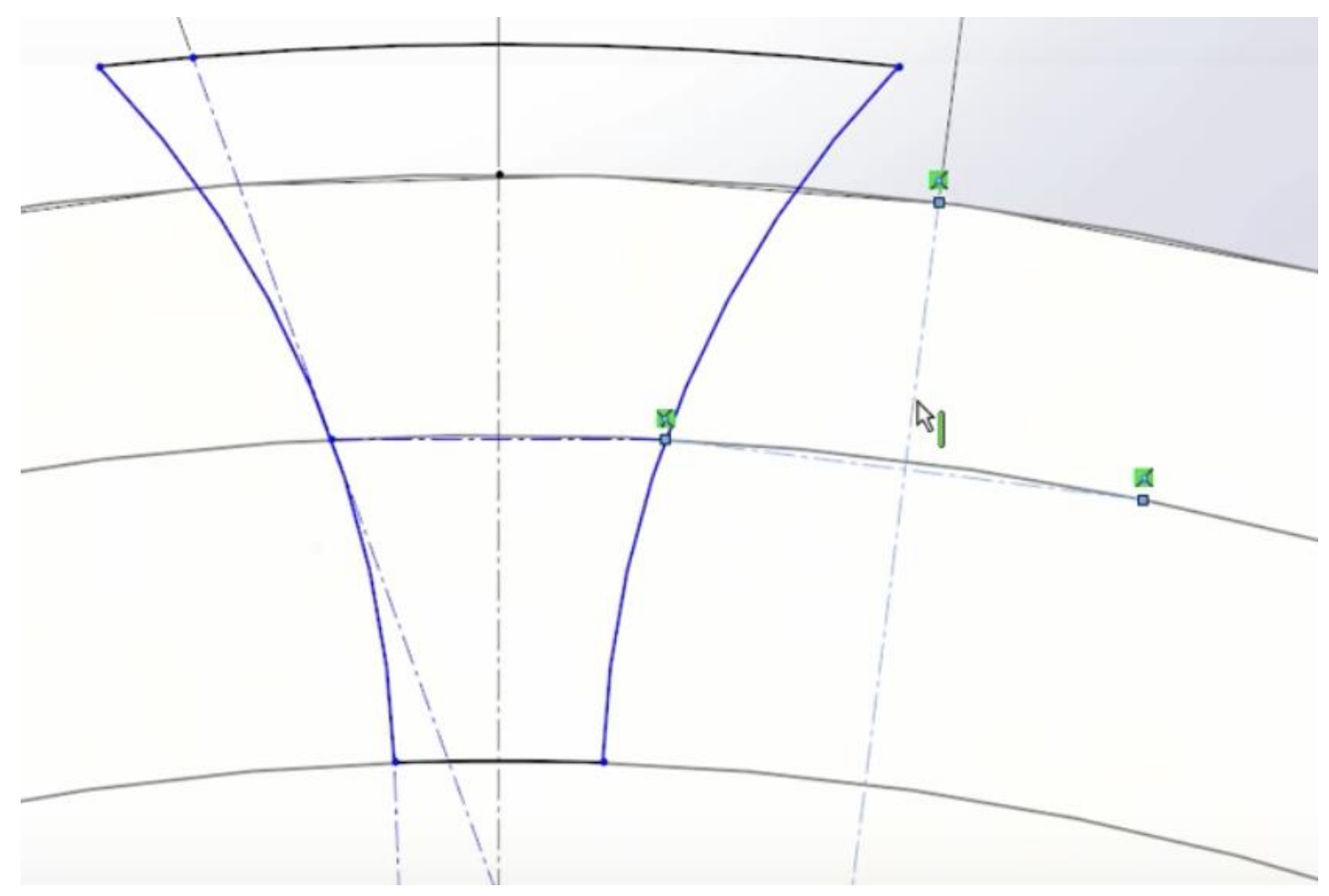

i. Create equal relationship to horizontal construction line in part a.

6. Extrude Cut Sketch 2

a. Though all both directions

7. Fillet Tooth

a. Select both bottom edges of tooth profile

b. Use Fillet equation to dimension

8. Pattern Teeth

a. Use circular pattern tool

i. Select cut and fillet

ii. Select outside face

iii. Specify $=$ Number of Teeth 


\section{VITA}

Antonio Francisco Coriano, son of Franky Coriano and Doreen Hausman-Chianese, is a young man with a passion for learning. A future professional in the field of Human Factors and Ergonomics, Antonio is a champion of sustainability. With great interest in human motivations, he hopes to work toward making socio-technical systems more sustainable through education. In the future, Antonio will pursue a $\mathrm{PhD}$ and find ways to both teach and learn throughout his life. Antonio's other interests include sport, fitness, nature, adventure, language, culture, and philosophy. 